\title{
Sapiens Mitochondrial DNA Genome Circular Long Range Numerical Meta Structures are Highly Correlated with Cancers and Genetic Diseases mtDNA Mutations
}

\author{
Jean-claude Perez* \\ IBM emeritus, Martignas Bordeaux metropole, France
}

\begin{abstract}
Using the circular nature of the 16k base-pairs human mtDNA genome, we are looking for hypothetical proportions between the $C+A$ and $T+G$ bases. Remarkable proportions are thus discovered, the length of which may be much greater than the length of the genome. We then analyze the impact of evolution on these "numerical resonances" by comparing the referenced mtDNAs of Sapiens, Neanderthal and Denisova. Then, by analyzing 250 characteristic mutations associated with various pathologies, we establish a very strong formal causal correlation between these numerical meta structures and these referenced mutations. To summarize, we should think then research on the following situation: (a) Inputs: 250 cases of mtDNA mutations1 associated with various human diseases. (b) An operator: The exhaustive search for mtDNA genome "Fibonacci resonances" associated with these mutations. (c) A "binary" output: a common behavior of the mtDNA genome resulting from these 250 mutations disorders.
\end{abstract}

Keywords: mtDNA; Cancer; Fractals; Fibonacci; Generic law

\section{Introduction}

Nearly 30 years ago, when we were just starting to have available genes and small genomes DNA sequences of viruses or bacteria, while the large project of human genome sequencing was just beginning, we showed the existence of specific numerical nucleotides proportions in the DNA of the genes [1,2]. This discovery also applied to small circular genomes such as those of bacteria or mitochondrial DNA genes-rich sequences. On the other hand, it did not work for non-coding DNA sequences regions like human chromosomes.

In the cells, mitochondria are known as the powerhouses of the cell. They are organelles that act like a digestive system which takes in nutrients, then breaks them down, and creates energy rich molecules for the cell. The biochemical processes of the cell are known like a cellular respiration.

The genome of the mitochondria or "mtDNA" is a small $16 \mathrm{~kb}$ genome whose remarkable feature is the fact that it is looped back on itself forming a circular sequence. This is also true of the genomes of most bacteria. As in prokaryotes, there is a very high proportion of coding DNA and an absence of repeats. It encodes 37 genes: 13 for subunits of respiratory complexes I, III, IV and V, 22 for mitochondrial tRNA (for the 20 standard amino acids, plus an extra gene for leucine and serine), and 2 for rRNA. One mitochondrion can contain two to ten copies of its DNA.

Mitochondrial genomes have been extensively studied and identified, especially for many years by Douglas C. Wallace [3-5]. This genome possesses the remarkable hereditary characteristic of being transmitted only by the mother [6], which makes it a privileged tool in the evolution studies of human species. Various heterogeneous genomes copies can be found in the same cell, it is heteroplasmia [7]. It would also appear that the genome of mitochondria and its mutations can play an important role in aging $[8,9]$. But, above all, simple mutations associated with various diseases (such as LHON) are observed, and somatic mutations are found in cells associated with various diseases such as cancers [10]. Effectvely, it is now emerging that somatic mutations in mitochondrial DNA (mtDNA) are also linked to other complex traits, including neurodegenerative diseases, ageing and cancer.

\section{Methods}

\section{The method of analysis}

Fibonacci and Lucas: The particular proportions that we are looking for here revolve around the numbers of Fibonacci and Lucas: (a) The Fibonacci numbers sequence: 01123581321345589144233377 61098715972584418167651094617711286574636875025121393 196418317811 (b) The Lucas numbers sequence: 2134711182947 7612319932252184313642207357157789349151272447639603. follows:

The specific proportions that we will search will be established as

1. From each base of the circular genome, delimiting a region of length $\mathrm{F}(\mathrm{i})$, if in this region we find $\mathrm{F}(\mathrm{i}-1)$ bases $\mathrm{C}$ or $\mathrm{A}$; Then we will say we have discovered a "resonance".

2. Consequently, this subsequence will also contain $\mathrm{F}(\mathrm{i}-2)$ bases $\mathrm{T}+\mathrm{G}$. For example, from base 10000 , we analyse the subsequence of the following 17711 nucleotides (considering the genome looped on itself thus of an "infinite" length).

3. Then, if we find within this sequence exactly 10946 bases $C$ or A, And, consequently, 6765 bases T or G.

*Corresponding author: Jean-claude Perez, PhD Maths and Computer Science retired interdisciplinary researcher (IBM emeritus), 7 avenue de terre-rouge F33127 Martignas Bordeaux metropole, France, Tel: 33 0781181112; E-mail: jeanclaudeperez2@gmail.com, jeanclaudeperez3@free.fr

Received May 19, 2017; Accepted June 07, 2017; Published June 12, 2017

Citation: Perez JC (2017) Sapiens Mitochondrial DNA Genome Circular Long Range Numerical Meta Structures are Highly Correlated with Cancers and Genetic Diseases mtDNA Mutations. J Cancer Sci Ther 9: 512-527. doi: 10.4172/19485956.1000469

Copyright: (c) 2017 Perez JC. This is an open-access article distributed under the terms of the Creative Commons Attribution License, which permits unrestricted use, distribution, and reproduction in any medium, provided the original author and source are credited. 
Citation: Perez JC (2017) Sapiens Mitochondrial DNA Genome Circular Long Range Numerical Meta Structures are Highly Correlated with Cancers and Genetic Diseases mtDNA Mutations. J Cancer Sci Ther 9: 512-527. doi: 10.4172/1948-5956.1000469

4. Then we declare to have discovered a "resonance of length $17711 "$

The different genomes analysed: Sapiens mtDNA genome called "Cambridge revised". It is found in the rCRS is GenBank number NC_012920 (7-11) [11-15]. Neanderthal 1 mtDNA genome [11]. DENISOVA1 and DENISOVA2 mtDNA genomes [12]. (a) DENISOVA1 alias "Denisova" in the original paper: Select item 9529523511. Homo sapiens ssp. Denisova isolate Denisova 8 mitochondrion, complete genome 16,573 bp circular DNA Accession: KT780370.1 GI: 952952351 (b) DENISOVA2 alias "ALTAI" in the original paper: Select item 2926064082. Homo sp. Altai mitochondrion, complete genome 16,570 bp circular DNA Accession: NC_013993.1 GI: 292606408. Chimpanzee mtDNA genome: >X93335.1 Pan troglodytes mitochondrial DNA, complete genome (isolate Jenny) [16].

The different diseases mutations analysed: A human mitochondrial genome database [17].

\section{Results}

We will present 4 types of progressive results:

Part 1: Evolution considerations comparing 5 humanoids mtDNA genomes.

Part 2: The exhaustive search for circular resonances of type $(\mathrm{C}+$ A)/TCAG.

Part 3: The exhaustive search for G/TCAG circular resonances.

Part 4: The search for Fibonacci "Hyper Constraints Super Resonances".

\section{Part 1: Evolution considerations comparing 5 humanoids mtDNA genomes}

Recall Fibonacci numbers sequence (Table 1, Figure 1): 01123 581321345589144233377610987159725844181676510946 17711286574636875025121393196418317811 . It is observed that, unlike Sapiens, the four ancestral genomes in the evolution are characterized by long circular resonances of 46,368 bases. Contrarily Sapiens is characterized by a number of 28657 bases long resonances very superior (152 resonances).

\section{Part 2: The exhaustive search for circular resonances of type (C+A)/TCAG}

Analysing 20 mtDNA mutations with reports of disease associations: Datas from MITOMAP database has provided by Fogleman et al. [18] and organized by mtDNA location by Fogleman et al. [18] (Supplementary Tables 1 and 2, Figures 2-4). It is noted that the resonances 10946 and 17711 INCREASE in the cases of mutations whereas the very long resonances 28657 DECREASE in the cases of mutations.

Analysing $44(25+19)$ mtDNA somatic mutations from 2 different mtDNA genome regions: The first 25 cases can be seen in Supplementary Table 3 and the other 19 cases can be seen in Supplementary Tables 4 and 5 (Figures 5-7). It is also noted here that the resonances 10946 and 17711 INCREASE in the case of mutations whereas the very long resonances 28657 DECREASE most often in the cases of mutations.

Analysing all LHON disease mtDNA mutations: Sources for analysis of $18+18=36$ cases of mutations associated with LHON (Leber's Hereditary Optic Neuropathy) are provided by Wallace et al.

\begin{tabular}{|c|c|c|c|c|c|c|}
\hline & $\begin{array}{l}\text { Genome length } \\
\text { (bases pairs) }\end{array}$ & $\begin{array}{c}\text { Number of } \\
\text { Resonance } 10946 \\
6765 \mathrm{C}+\mathrm{A} 4181 \mathrm{~T}+\mathrm{G}\end{array}$ & $\begin{array}{c}\text { Number of Resonance } \\
1771110946 \text { C+A } 6765 \\
\text { T+G }\end{array}$ & $\begin{array}{c}\text { Number of Resonance } \\
2865717711 \text { C+A } 10946 \\
\text { T+G }\end{array}$ & $\begin{array}{c}\text { Number of Resonance } \\
4636828657 \text { C+A } 17711 \\
\text { T+G }\end{array}$ & $\begin{array}{c}\text { Number of Resonance } \\
7502546368 \text { C+A } 28657 \\
\text { T+G }\end{array}$ \\
\hline Sapiens & 16568 & 10 & 8 & 152 & 0 & 0 \\
\hline Neanderthal 1 & 16565 & 2 & 16 & 23 & 92 & 0 \\
\hline Denisova 1 & 16573 & 52 & 33 & 41 & 36 & 0 \\
\hline Denisova 2 & 16570 & 10 & 62 & 10 & 68 & 0 \\
\hline Chimp & 16561 & 33 & 76 & 33 & 46 & 0 \\
\hline
\end{tabular}

Table 1: Table comparing ( $\mathrm{C}+\mathrm{A}) / \mathrm{TCAG}$ long range Fibonacci resonances for 5 reference humanoids mtDNA genomes.

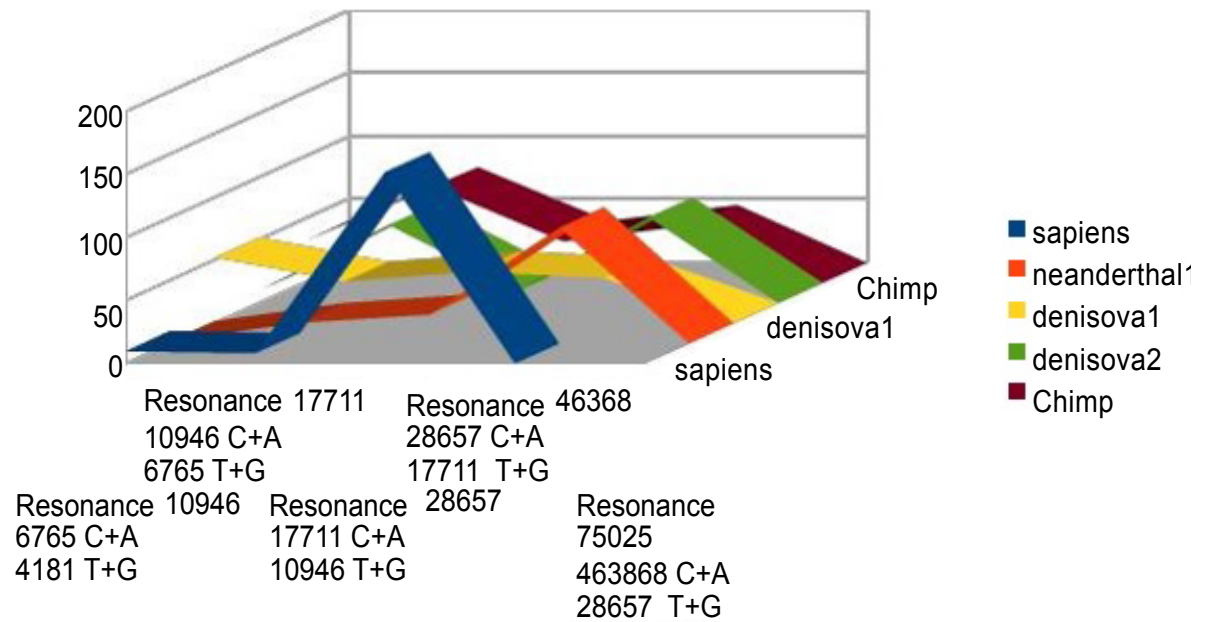

Figure 1: Graph comparing $(\mathrm{C}+\mathrm{A}) / \mathrm{TCAG}$ long range Fibonacci resonances for 5 reference humanoids mtDNA genomes. 


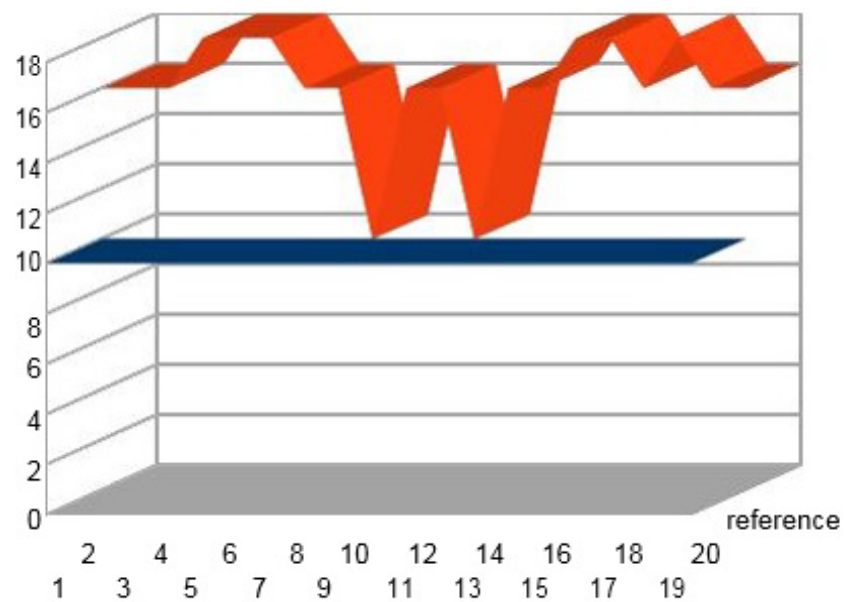

reference

resonances 10946

Figure 2: Resonances 10946 for 20 cases of reported mitochondrial DNA base substitution diseases: rRNA/tRNA mutations.

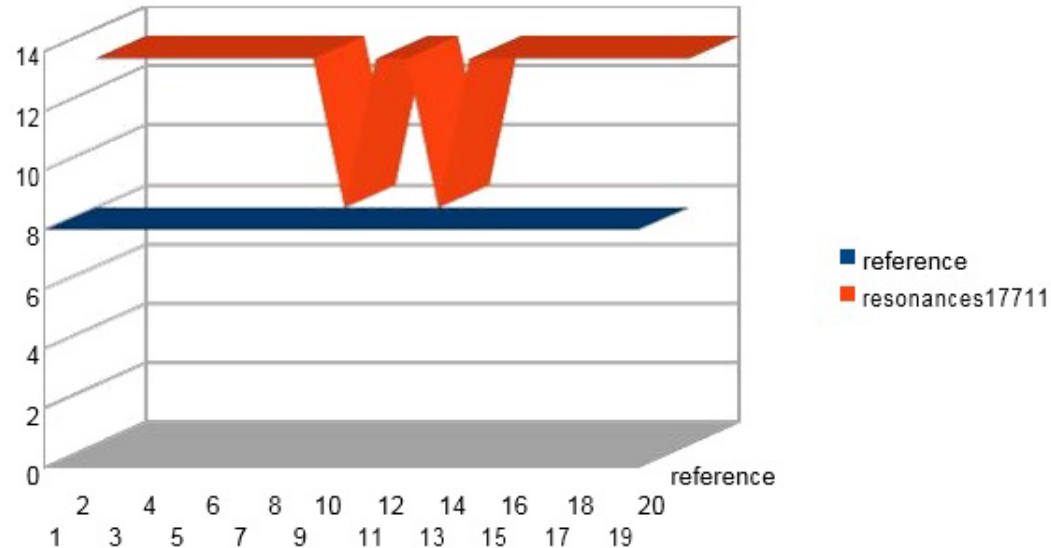

Figure 3: Resonances 17711 for 20 cases of reported mitochondrial DNA base substitution diseases: rRNA/tRNA mutations.

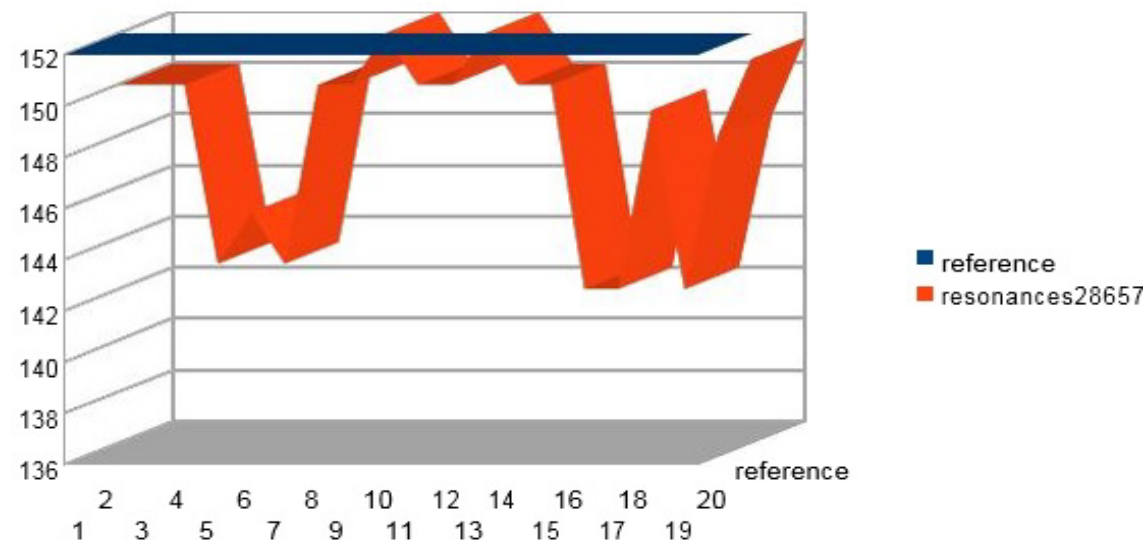

Figure 4: Resonances 28657 for 20 cases of reported mitochondrial DNA base substitution diseases: rRNA/tRNA mutations.

$[19,20]$ and can be seen in Supplementary Table 6. Other candidate LHON mutations are found as single family or silngleton cases which are seen in Supplementary Tables 7 and 8 (Figures 8-10). It is noted that the resonances 10946 and 17711 INCREASE in all the cases of mutations whereas the very long resonances 28657 DECREASE in the majority of the mutations cases (Table 2). (a) Synthesis: It is finally observed that all 100 mutations increase or retain resonances 10946 and $17711(100 \%)$ while they decrease more generally the very long resonances 28657 (63\%).

Lucas verification extension: The sequence of Lucas convergeslike the sequence of Fibonacci-towards the value of the golden number 
Citation: Perez JC (2017) Sapiens Mitochondrial DNA Genome Circular Long Range Numerical Meta Structures are Highly Correlated with Cancers and Genetic Diseases mtDNA Mutations. J Cancer Sci Ther 9: 512-527. doi: 10.4172/1948-5956.1000469

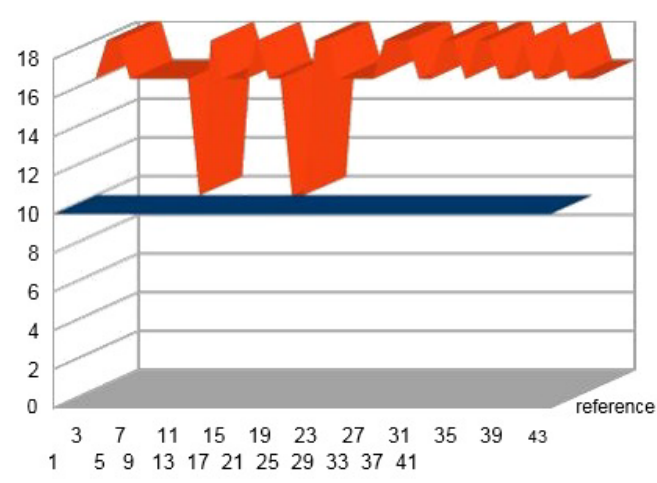

- reference

resonances 10946

Figure 5: Graphic of resonances 10946 for 44(25+19) mtDNA somatic mutations.

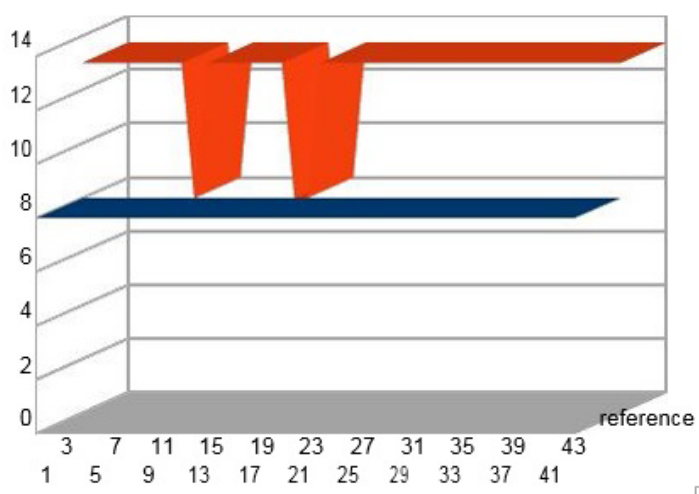

- reference

resonances 17711

Figure 6: Graphic of resonances 17711 for 44(25+19) mtDNA somatic mutations.

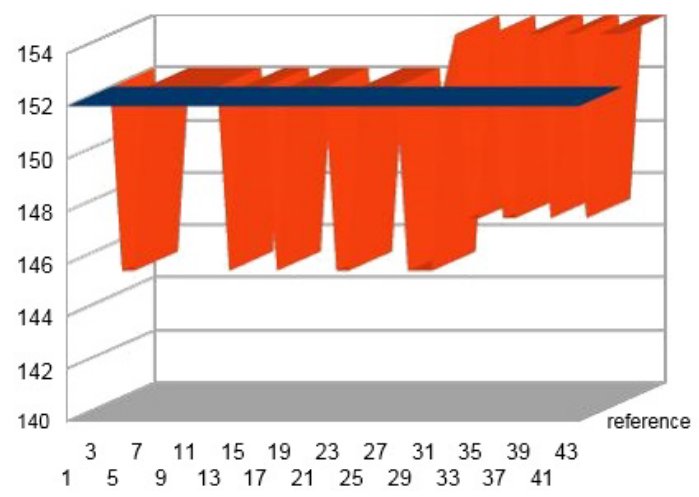

- reference

resonances 28657

Figure 7: Graphic of resonances 28657 for 44(25+19) mtDNA somatic mutations.

1.618033 ... However, its convergence is significantly less rapid than that of the Fibonacci series. It is therefore seemed useful to analyze also the impact of mutations of the human mtDNA genome on hypothetical resonances following this sequence of Lucas. LUCAS: 213471118 294776123199322521843136422073571577893491512724476 39603 We have figured in this series of Lucas the values to which we are interested, they are shown above in bold type. We will limit this analysis to the study of the somatic mutations described in the Tables 3 and 4 (Supplementary Table 9, Figures 11-13). It will be noted (diametrically opposed to the study of the resonances of Fibonacci) that here resonances 9349 and 15127 DECREASE in the cases of mutations whereas the very long resonances 24476 INCREASE in the cases of mutations.
Merger of 2 Fibonacci and Lucas studies: It seemed interesting to us to merge on one and the same table both resonances of Fibonacci (Table 5) and Lucas. Recall Fibonacci and Lucas numbers: (a) FIBONACCI: 01123581321345589144233377610987 159725844181676510946177112865746368 (b) LUCAS: 213 47111829477612319932252184313642207357157789349 151272447639603.

We have shown in these two sequences of Fibonacci and Lucas the values to which we are interested, they appear above in bold type (Supplementary Table 10). Comparison of 2 to 2 the results for neighboring Fibonacci and Lucas numbers can be seen in Figures 14-16. 
Citation: Perez JC (2017) Sapiens Mitochondrial DNA Genome Circular Long Range Numerical Meta Structures are Highly Correlated with Cancers and Genetic Diseases mtDNA Mutations. J Cancer Sci Ther 9: 512-527. doi: 10.4172/1948-5956.1000469

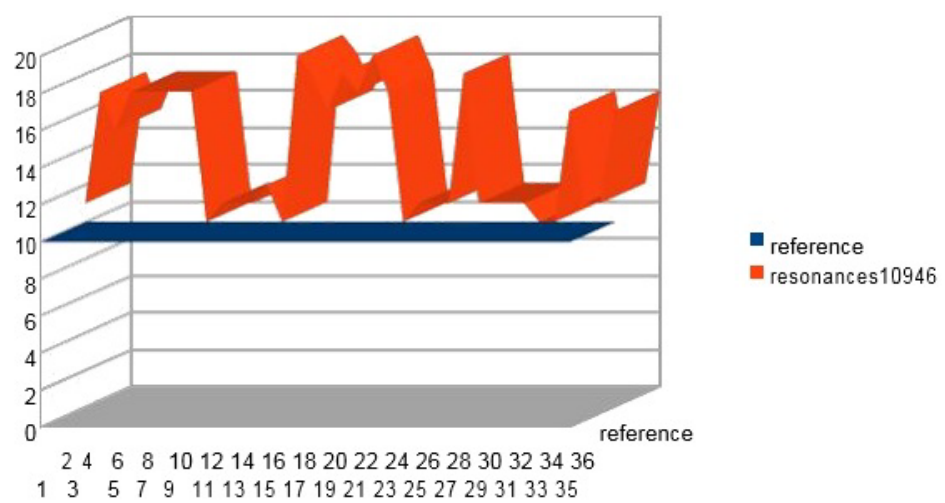

Figure 8: Graphics related 10946 resonances for 36 cases of mutations associated with the LHON disease (Leber's hereditary optic neuropathy).

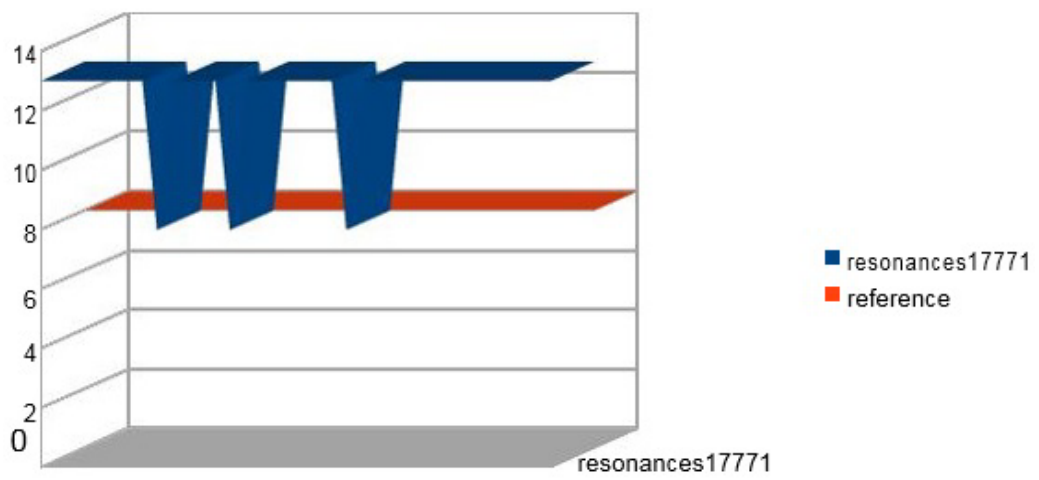

24681012141618202224262830323436

1357911131517192123252729313335

Figure 9: Graphics related 17771 resonances for 36 cases of mutations associated with the LHON disease (Leber's hereditary optic neuropathy)

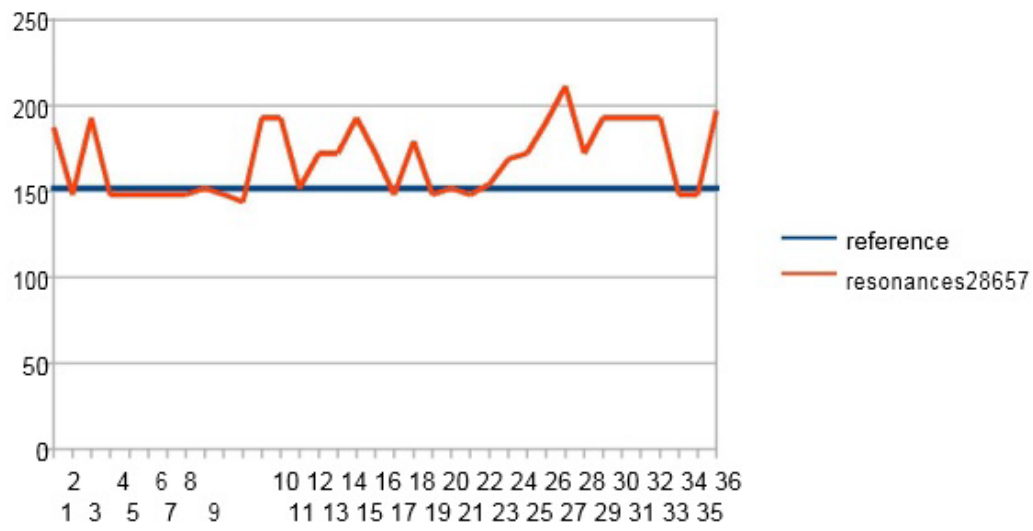

Figure 10: Detail of graphics related 28657 resonances for 36 cases of mutations associated with the LHON disease (Leber's hereditary optic neuropathy).

\begin{tabular}{|c|c|c|c|c|c|c|c|c|c|}
\hline & \multicolumn{3}{|c|}{ Number of Resonances 10946} & \multicolumn{3}{|c|}{ Number of Resonances 17711} & \multicolumn{3}{|c|}{ Number of Resonances 28657} \\
\hline & Decrease & Neutral & Increase & Decrease & Neutral & Increase & Decrease & Neutral & Increase \\
\hline $1 / 20$ disease mutations & 0 & 2 & 18 & 0 & 2 & 18 & 18 & 2 & 0 \\
\hline $2 / 44$ somatic mutations & 0 & 3 & 41 & 0 & 3 & 41 & 32 & 3 & 9 \\
\hline 3/all 36 LHON mutations & 0 & 3 & 33 & 0 & 3 & 33 & 13 & 3 & 20 \\
\hline Cumul by 100 & 0 & 8 & 92 & 0 & 8 & 92 & 63 & 8 & 29 \\
\hline Score $=($ increase + neutral $) /($ total $)$ & $100,00 \%$ & & & $100,00 \%$ & & & $37 \%$ & & \\
\hline Score $=($ decrease $) /($ total $)$ & $0,00 \%$ & & & $0,00 \%$ & & & $63 \%$ & & \\
\hline
\end{tabular}

Table 2: Synthesis of the cumulate 100 mutations cases. 
Citation: Perez JC (2017) Sapiens Mitochondrial DNA Genome Circular Long Range Numerical Meta Structures are Highly Correlated with Cancers and Genetic Diseases mtDNA Mutations. J Cancer Sci Ther 9: 512-527. doi: 10.4172/1948-5956.1000469

\begin{tabular}{|c|c|c|}
\hline & $\begin{array}{c}\text { Genome length (bases } \\
\text { pairs) }\end{array}$ & $\begin{array}{c}\text { Number of Hyper-resonances } \\
\mathbf{6 7 6 5}\end{array}$ \\
\hline Sapiens & 16568 & 7 \\
\hline Neanderthal 1 & 16565 & 1 \\
\hline Denisova1 & 16573 & 0 \\
\hline Denisova 2 & 16570 & 0 \\
\hline Chimp & 16561 & 0 \\
\hline
\end{tabular}

Table 3: Fibonacci « hyper constraints super resonances » in the cases of 5 reference mtDNA genomes.

\begin{tabular}{|l|c|c|c|}
\hline \multirow{2}{*}{} & \multicolumn{3}{|c|}{$\begin{array}{c}\text { The 7 hyper-resonances of } \mathbf{6 7 6 5} \text { in } \\
\text { the } \mathbf{2 5 0} \text { analysed mutations }\end{array}$} \\
\cline { 2 - 4 } & Decrease & Neutral & Increase \\
\hline 1/20 disease mutations & 20 & 0 & 0 \\
\hline 2/44 somatic mutations & 42 & 2 & 0 \\
\hline 3/all 36 LHON mutations & 9 & 27 & 0 \\
\hline 4/100 other somatic mutations & 84 & 16 & 0 \\
\hline 5/50 somatic mutations in the hyper-loop & 43 & 7 & 0 \\
\hline total & 198 & 52 & 0 \\
\hline Score = decrease/Total & \multicolumn{3}{|c|}{$100,00 \%$} \\
\hline Score=(decrease+neutral)/Total & \multicolumn{3}{|c|}{$10 \%$} \\
\hline
\end{tabular}

Table 4: Final results analysing Fibonacci « hyper constraints super resonances » from 250 mutations cases.
The reader will find that these Fibonacci and Lucas couples of resonances are always systematically opposed, some decreasing during mutations while others increase for these same mutations, and vice versa. An attempt at explanation: although the rates of convergence towards Phi $=1.618033$ the golden ratio are very similar for the Lucas and Fibonacci sequences [21], these opposite effects can be explained by the kinds of "combs or Grids "of selectivities formed by successive alternations of successive numbers of Fibonacci and Lucas, for example: Fibonacci: 1094617711 28657; Lucas: 93491512724476.

This suggests a certain "undulatory" nature [22] of these alternate "windows" of respective sensitivities of successively alternating numbers of Fibonacci and Lucas.

\section{Part 3: The exhaustive search for G/TCAG circular resonances}

One question arises: The mtDNA genome being looped back on itself, and the sequences of Fibonacci and Lucas being infinite on the other hand, it is possible (and it is even certain theoretically) that very Long circular resonances may exist. Can there be very long resonances of several million bases? We have tested this possibility by looking at the 5 reference genomes for hypothetical resonances of Fibonacci whose length could reach 15 million bases for a genome whose length is only 16000 bases (Table 6).

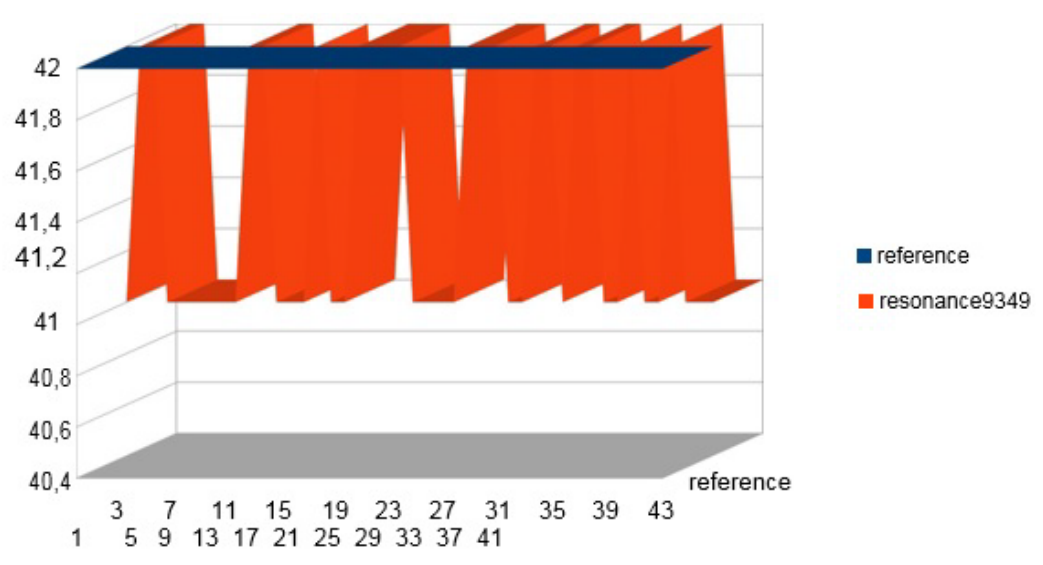

Figure 11: $(A+C) / T C A G 9349$ Lucas resonances for the 44(19+25) mtDNA somatic mutations of Table 5.

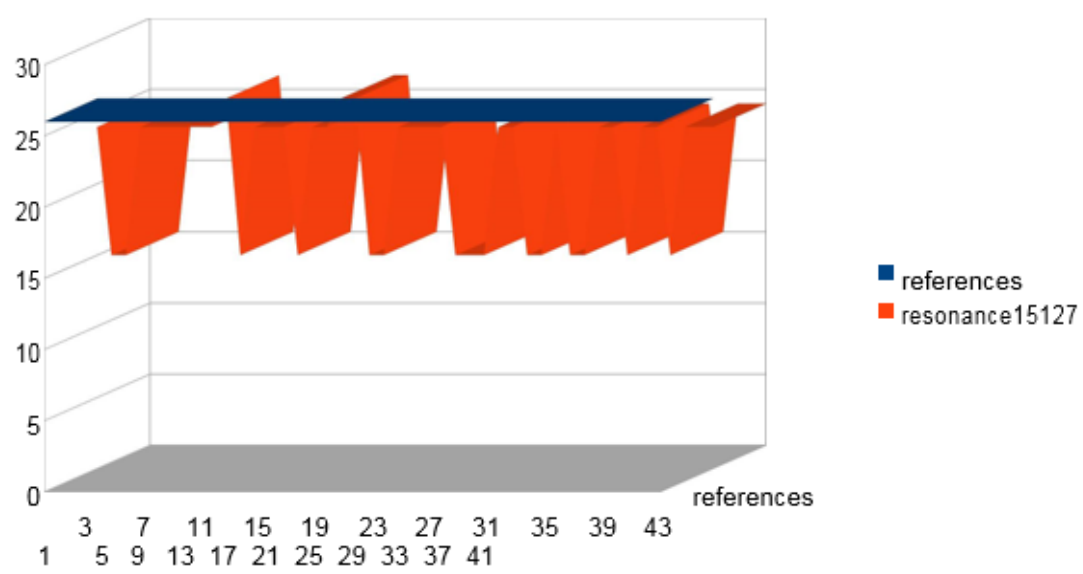

Figure 12: $(A+C) / T C A G 15127$ Lucas resonances for the 44(19+25) mtDNA somatic mutations of Table 5. 
Citation: Perez JC (2017) Sapiens Mitochondrial DNA Genome Circular Long Range Numerical Meta Structures are Highly Correlated with Cancers and Genetic Diseases mtDNA Mutations. J Cancer Sci Ther 9: 512-527. doi: 10.4172/1948-5956.1000469

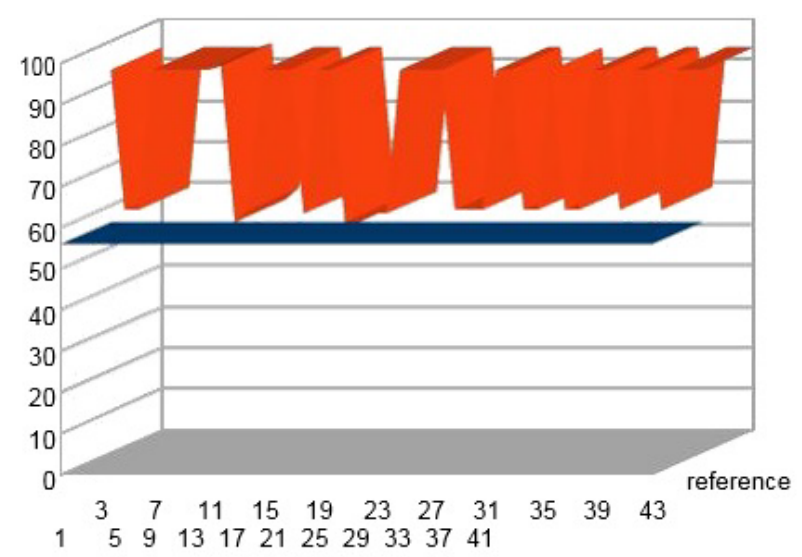

- reference

resonaces 24476

Figure 13: $(A+C) / T C A G 24476$ Lucas resonances for the 44(19+25) mtDNA somatic mutations of Table 5

\begin{tabular}{|c|c|c|c|c|c|c|c|c|}
\hline & $\begin{array}{c}\text { Dim mtDNA } \\
\text { genome }\end{array}$ & T base & A base & C base & G base & Ratio T/A & Ratio C/G & $\begin{array}{c}\text { Chargaff rule T=A and C=G on } \\
\text { single strand DNA }\end{array}$ \\
\hline $\begin{array}{c}\text { Circular regular mtDNA } \\
\text { genome }\end{array}$ & 16568 & 4094 & 5124 & 5181 & 2169 & 0.7989852 & 2.3886584 & No \\
\hline $\begin{array}{c}\text { Moebius-like ribbon } \\
\text { mtDNA genome 4 }\end{array}$ & 33136 & 9218 & 9218 & 7350 & 7350 & 1 & 1 & Yes \\
\hline
\end{tabular}

Table 5: Chargaff rule of single stranded mtDNA genomes in regular and Moebius strip cases.
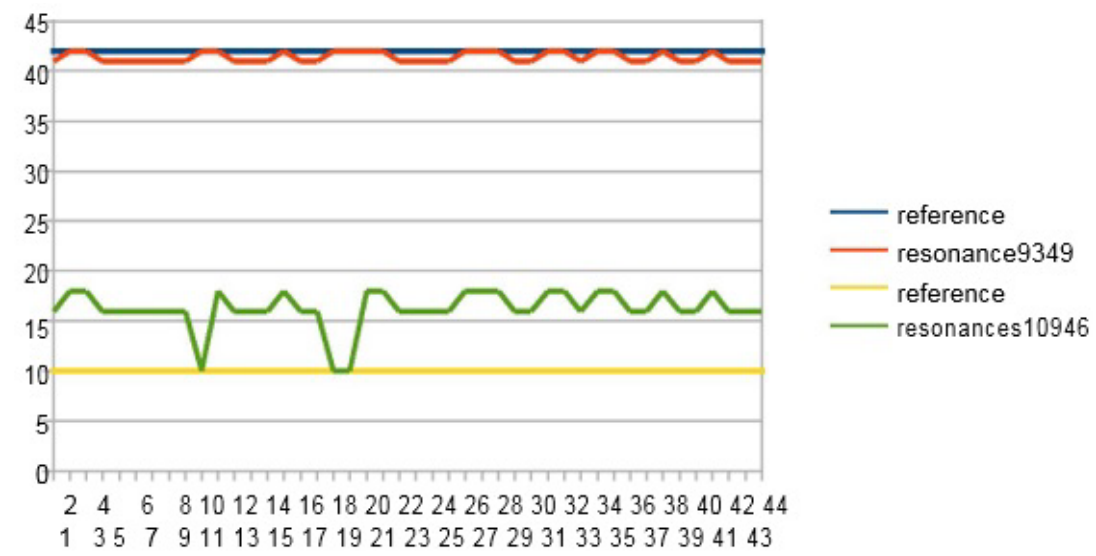

Figure 14: Comparative analysis of Fibonacci (10946) and Lucas (9349) resonances (A+C)/TCAG for the 44 mtDNA somatic mutations of manuscript Table 4.

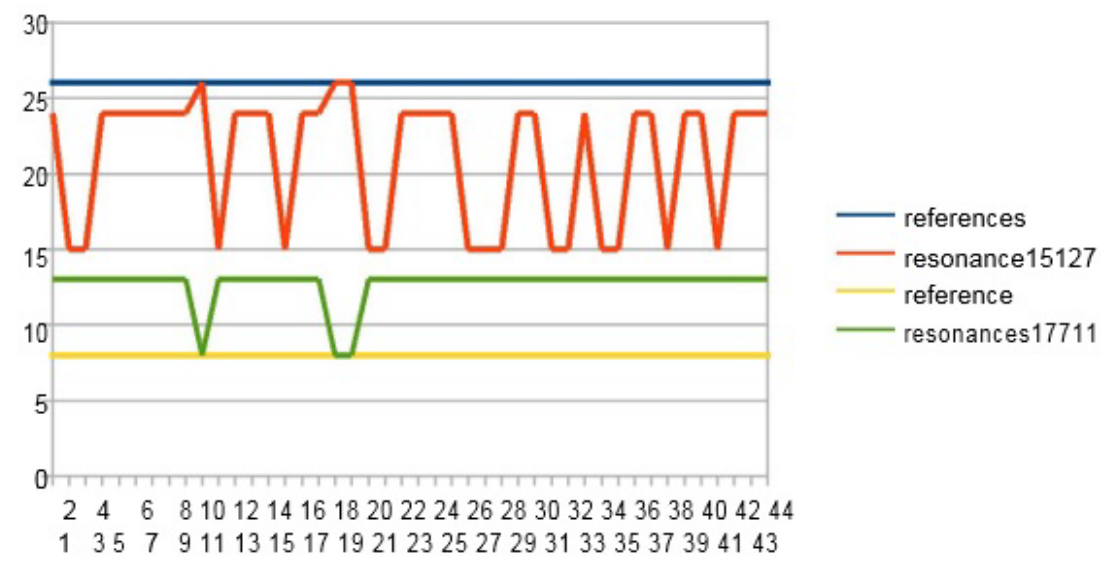

Figure 15: Comparative analysis of Fibonacci (17711) and Lucas (15127) resonances (A+C)/TCAG for the 44 mtDNA somatic mutations of manuscript Table 4. 
Citation: Perez JC (2017) Sapiens Mitochondrial DNA Genome Circular Long Range Numerical Meta Structures are Highly Correlated with Cancers and Genetic Diseases mtDNA Mutations. J Cancer Sci Ther 9: 512-527. doi: 10.4172/1948-5956.1000469

Yet, over 18 years ago, in 1999 we wrote: "Fossil NEANDERTAL's mtDNA" and in 1997 then in 1999, the German researcher Svante Paabo $[13,14]$ analyzed two small fragments of the hyper-variable region of mtDNA taken on first Neandertalian discovered in 1856 close to Dusseldorf (and preciously preserved today). It is this specimen, old man of approximately 30000 years who was going to give birth at the end "Man of NEANDERTAL "(in memory of "Neandertal ", the area of Germany where it was discovered for the first time). While being based on the analysis of these two small DNA areas and on their level of homology to DNA from the "current Sapiens", Dr Paabo was going to show that NEANDERTAL and SAPIENS would be two parallel lines which would have coexisted during a few millenium. But their common stock would be much older (approximately 600000 years) and, consequently, Homo Sapiens would not go down from HomoNeandertal!

The man of Neandertal would be located approximately halfway between Homo-Sapiens and our nearer close, the chimpanzee. Immense polemic in the "Evolution Scientists microcosm", which, as each one knows, lets evolve/move its dogmas only very slowly. Recently, in 1999, two other major publications on the subject have just established, on the one hand, then NEANDERTAL and SAPIENS had coexisted (then, probably, produced "Neandertal-Sapiens children" [15]), and, on the other hand, than NEANDERTAL was cannibal. [17].

Materials and Methods: The suggested Transgene: Apply the following precise protocol, consider:

1. A complete genome of mtDNA from the chimpanzee "Pan Troglodyte JENNY” (GenBank X93335). This circular genome measures 16561 bases, baptize to it "CHIMP".
2. Take the 2 fossil DNA sections of Neandertal extracted by Svante Pääbo starting from the fossil skeleton from the man from Neandertal. The co-ordinates and precise references of these 2 sequences are respectively:

i. HVR1- 379 bases- S. Paabo in CELL 1997 Jul 11; 90(1): 19-30 [13].

ii. HVR2- 345 bases- S. Paabo in PNAS 1999 flight 96 pp. 55815585 [14]

3. Form transgene "G.M. hOmo-NEANDERTAL" by amalgamating the genome [1] of the chimpanzee and the 2 sections (2.i and 2.ii) of NEANDERTAL as follows:

i. Just after base 15447 of CHIMP, to replace the 376 following bases by 379 bases HVR1 of the NEANDERTAL.

ii. Just after base 16050 of CHIMP (original), to replace the 335 following bases by 345 bases HVR2 of the NEANDERTAL.

The new "transgenome" thus trained, "G.M. homoNEANDERTAL" account now 16574 bases (instead of the 16561 initial bases).

This hybrid DNA is circular. One can seek there the "DNA SupraCode" resonances. The thousands of "resonances" of the SUPRACODE of DNA structures and structures the relative arrangement of bases TCAG within DNA; we recall their computing protocol: each resonance is a remarkable arrangement of a contiguous sequence of bases TCAG following a proportion of Fibonacci's or Lucas's numbers (for example, 89 bases TCAG will be subdivided in 34 bases T and in 55 bases ACG. 3455 and 89 are three successive numbers in the continuation of Fibonacci 1123581321345589144 233...).

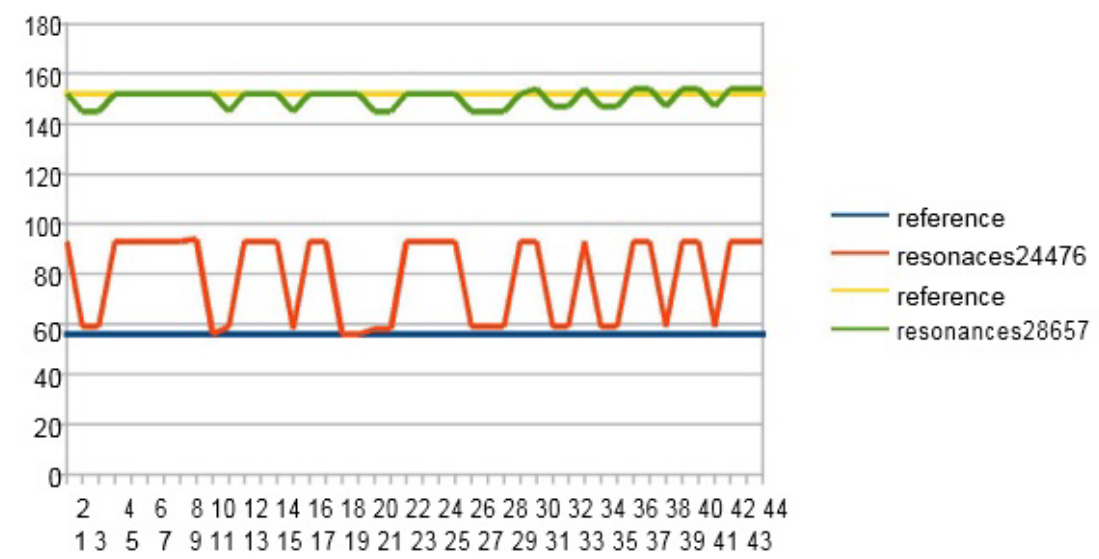

Figure 16: Comparative analysis of Fibonacci (28657) and Lucas (24476) resonances (A+C)/TCAG for the 44 mtDNA somatic mutations of manuscript Table 4.

\begin{tabular}{|c|c|c|c|c|c|c|c|c|c|c|c|c|c|c|c|c|}
\hline \multirow{2}{*}{ Memo chimp } & 10946 & 17711 & 28657 & 46368 & 75025 & 121393 & 196418 & 317811 & 514229 & 832040 & 1346269 & 2178309 & 3524578 & 5702887 & 9227465 & 14930352 \\
\hline & 33 & 76 & 33 & 46 & 0 & 0 & 0 & 0 & 0 & 0 & 0 & 0 & 0 & 0 & 0 & 0 \\
\hline \multirow{2}{*}{$\begin{array}{l}\text { Sapiens memo } \\
\text { mtDNA }\end{array}$} & 10946 & 17711 & 28657 & 46368 & 75025 & 121393 & 196418 & 317811 & 514229 & 832040 & 1346269 & 2178309 & 3524578 & 5702887 & 9227465 & 14930352 \\
\hline & 10 & 8 & 152 & 0 & 0 & 0 & 0 & 0 & 0 & 0 & 0 & 0 & 0 & 0 & 0 & 0 \\
\hline \multirow{2}{*}{$\begin{array}{c}\text { Memo } \\
\text { Neanderthal } 1\end{array}$} & 10946 & 17711 & 28657 & 46368 & 75025 & 121393 & 196418 & 317811 & 514229 & 832040 & 1346269 & 2178309 & 3524578 & 5702887 & 9227465 & 14930352 \\
\hline & 2 & 16 & 23 & 92 & 0 & 0 & 0 & 0 & 0 & 0 & 0 & 0 & 0 & 0 & 0 & 0 \\
\hline \multirow{2}{*}{$\begin{array}{c}\text { Memo } \\
\text { Denisova } 1\end{array}$} & 10946 & 17711 & 28657 & 46368 & 75025 & 121393 & 196418 & 317811 & 514229 & 832040 & 1346269 & 2178309 & 3524578 & 5702887 & 9227465 & 14930352 \\
\hline & 52 & 33 & 41 & 36 & 0 & 0 & 0 & 0 & 0 & 0 & 0 & 0 & 0 & 0 & 0 & 0 \\
\hline \multirow{2}{*}{$\begin{array}{c}\text { Memo } \\
\text { Denisova } 2\end{array}$} & 10946 & 17711 & 28657 & 46368 & 75025 & 121393 & 196418 & 317811 & 514229 & 832040 & 1346269 & 2178309 & 3524578 & 5702887 & 9227465 & 14930352 \\
\hline & 10 & 62 & 10 & 68 & 0 & 0 & 0 & 0 & 0 & 0 & 0 & 0 & 0 & 0 & 0 & 0 \\
\hline
\end{tabular}


There because of the circular structure, in theory, resonances INFINITE LENGTH could even emerge here. My recent discovered led me to interest me in particular in resonances between the bases $\mathrm{T}+\mathrm{G}$ on the one hand, $\mathrm{A}+\mathrm{C}$ on the other hand, and the totality of bases TCAG. For a set of native mt-genomes studied (including worm-of ground, crocodile and monkeys or human mt-genomes), I discover indeed a great number of such resonances of which the maximum length is 28657 for the man and 75025 in the case of great apes (what is equivalent to more than one turn of genome since these genomes measure all approximately 16000 bases). All these numbers 28657, 75025 etc are whole numbers belonging to the series of Lucas (1 347 $11 \ldots)$ or of Fibonacci ( 11123358 13...).

What does occur if one "dopes" these genomes by the 2 fragments of NEANDERTAL? For the few twenty species which we studied, the results are very variable then insignificant. However, the higher primates (monkeys) and the man are those at which one observes longest resonances and the greatest influence of this "Neandertal transgene". In certain cases, even, this ancestral transgene acts like true "a dopant". Particularly, for the genome of the chimpanzee mentioned above, "immense resonances" then will emerge: one will count even 88 hyper-resonances which will reach the length record of 2178309 bases (TWO MILLION and 178.309 bases). If, now, one "dopes" this transgenic genome by changing only one A base to $G$ on a location where this type of mutation is often observed, that will be enough then to give birth to 105 resonances from 3524578 bases and 25 other resonances of 4870847 bases. Then, there are immense resonances reaching nearly FIVE MILLION BASES what, for a genome of 16574 bases of circumference, is equivalent to nearly 294 turns of the genome! If we add that this phenomenon probably corresponds to properties of circulation of ELECTRONS, there gradually, between the bases. But how thus of so gigantic resonances they could emerge? If we have curiosity to enter the respective amounts of bases TCAG composing this genome, and, particularly, respective sums $\mathrm{T}+\mathrm{G}$ on the one hand and $\mathrm{A}+\mathrm{C}$ on the other hand, one will note that ratios $(\mathrm{T}+\mathrm{C}+\mathrm{A}+\mathrm{G}) /$ $(\mathrm{A}+\mathrm{C})$ and $(\mathrm{A}+\mathrm{C}) /(\mathrm{T}+\mathrm{G})$ all the more approach exactly the Golden section $\mathrm{PHI}=1.618033989$ which resonances become increasingly long. For example, this ratio, for the mtDNA related to the current chimpanzee and to the current human mt-DNA genomes is worth respectively 1.612 (chimpanzee) and 1.608 (man), values already very close to Phi=1.618. Then, it appears that, in the "ideal" case of the "G.M. hOmo-NEANDERTAL" trans-genome, who counts 16574 bases, these bases are distributed in a quasi-ideal way in 10244 bases AC and 6330 bases TG.
Consequently, reports/ratios: TCAG/AC=16574/10244=1.617922 and $\mathrm{AC} / \mathrm{TG}=10244 / 6330=1.618325$

All that is quite close to the ideal ratio of the Golden Section $\mathrm{Phi}=1.618033989$. It does not miss, in fact, that only one base $\mathrm{G}$ or $\mathrm{T}$ more (and a base A or C in less) "to perfect" this ratio. We have find the OPTIMAL TCAG balancing point: it is, very precisely, which occurred when one reached a length close to FIVE MILLION BASES by doping transgene of only one change A to $\mathrm{G}$ (one reached ratio 1.618080 then).

What to think of a so beautiful clock-like sophisticated mechanism? 18 years later, this catastrophe scenario became possible thanks to the CRISPR technology which could realize such manipulation worthy of the most illustrious novels of science fiction [18].

Also in 1999, we carried out another study on the mtDNA, it was never published, it consisted of looking for resonances of the Fibonacci type on the bases "G". For example, search for 987 bases " $G$ " in a contig of length 6765 bases T C A or G. Here, 9871597258441816765 are successive numbers of the Fibonacci sequence. We then found very large amounts of such resonances that we also correlated with the somatic mutations of mtDNA associated with various diseases.

Here is an overview, a short excerpt from this 1999 study: We report here a set of sixteen "cross-diseases" examples where small localized mutations in the D-loop areas (five changes and one deletion within bases $16 x x x$ region) or various others referenced to be related to mitochondrial diseases, destroy partially a set of long range high level structures (length 6765 bases for a 16569 bases length genome). These "RESONANCES" are particular proportions between the number of G bases (987) and the total bases number in the resonance (6765), where 987 and 6765 are values of the "FIBONACCI's integer numbers series". The following figure summarizes the results (Figure 17, Supplementary Table 11).

It is thus observed that resonances of the mtDNA on lengths of Fibonacci of 6765 bases may be sometimes of type G/TCAG or sometimes of type $(\mathrm{C}+\mathrm{A}) / \mathrm{TCAG}$.

The questions that we will now ask ourselves: "can there exist resonances that are simultaneously of type G/TCAG and type (C+A)/ TCAG. This would be all the more interesting since in 1999 [23] it has been demonstrated by Ratner that the possibility of some sort of electrical flux traveling through the bases "G" in the DNA. If this DNA is further looped back on itself, this electrical property could even give rise to "electrical oscillator" kinds!

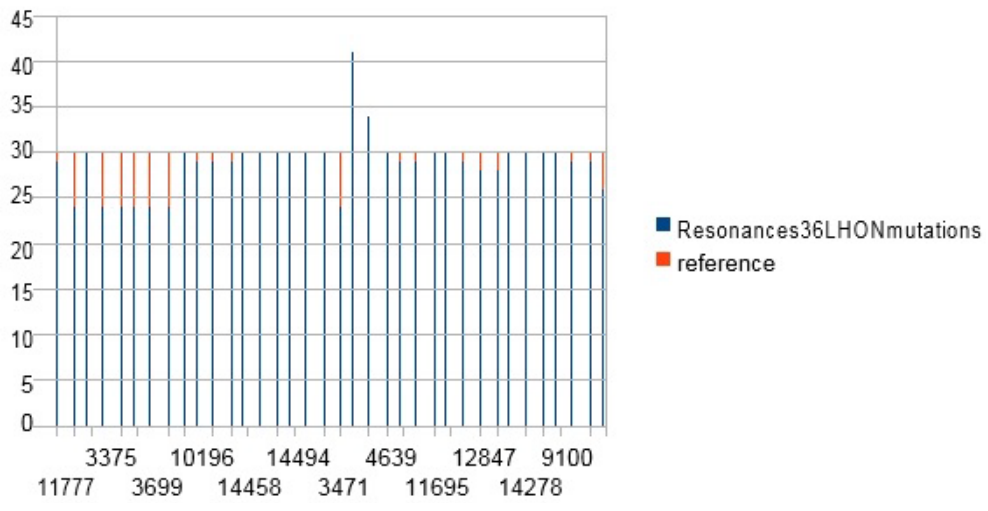

Figure 17: Example of C+A/TCAG 6765 resonances for the LHON mutations (Tables 7 and 8). 
Citation: Perez JC (2017) Sapiens Mitochondrial DNA Genome Circular Long Range Numerical Meta Structures are Highly Correlated with Cancers and Genetic Diseases mtDNA Mutations. J Cancer Sci Ther 9: 512-527. doi: 10.4172/1948-5956.1000469

\section{Part 4: The search for Fibonacci "Hyper Constraints Super Resonances"}

Let us recall the values of the Fibonacci sequence: 011235813 2134558914423337761098715972584418167651094617711 286574636875025121393196418317811 . Look for resonances that would obey simultaneously the two types of independent constraints analysed here: $1 /(\mathrm{C}+\mathrm{A}) / \mathrm{TCAG}$ resonances on the one hand, $2 / \mathrm{G} /$ TCAG resonances on the other hand.

Then we would have: For populations in the following Fibonacci numbers: 987159725844181 6765. If the region has 6765 contiguous TCAG bases, AND $4181(\mathrm{C}+\mathrm{A})$ bases THEN, it will also necessarily count 2584 bases $(T+G)$ AND IF these 2584 bases $(T+G)$ are subdivided into 987 bases G AND 1597 bases T THEN, we will claim to have discovered a "super resonance hyper constraint" long of 6765 bases.

Do such resonances exist? In the case of the mtDNA genome of SAPIENS, there are 7 hyper resonances of 6765 bases. Here is the detail and positions and TCAG distributions of these resonances:

$\begin{array}{llll}\mathrm{T} & \mathrm{C} & \mathrm{A} & \mathrm{G} \\ 1597 & 2043 & 2138 & 987 \\ 1597 & 2043 & 2138 & 987 \\ 1597 & 2044 & 2137 & 987 \\ 1597 & 2044 & 2137 & 987 \\ 1597 & 2044 & 2137 & 987 \\ 1597 & 2045 & 2136 & 987 \\ 1597 & 2044 & 2137 & 987\end{array}$

It will be noted that in these 7 resonances, $\mathrm{T}$ and $\mathrm{G}$ are Fibonacci numbers as well as the sum $(\mathrm{A}+\mathrm{C})$. The starting addresses of these resonances are: 147531475414755147561475714758 14759. It will be noticed here that these resonances can exist only thanks to the rebouche nature of the genome: in effer $14753+6765>16568$ the length of the genome mtDNA.

The other 4 genomes of the Chimpanzee, Neanderthal and Denisova 1 and Denisova 2 are seen in Table 4 . It is found that only Neanderthal 1 contains such resonance. Let us now analyze the 100 cases of mutations presented in the section "results" (Figures 18-21).
Scope of effect of these 7 resonances: $14753+6765=21518$; 21518 $16568=4950$. Then these 7 resonances overlapped regions 14753 to the end of the genome (164568) and the starting region of the genome: 1 to 4950. And this for 7 contiguous bases 1475314754147551475614757 1475814759 .

We now extend this analysis to 150 cases of additional mutations, finally a total of $100+150=250$ mutations cases. The first study 100 new cases of somatic mutations studied are provided by Koehler et al. [24] and from Figures 22 and 23 and Supplementary Table 12 and then other 50 new cases located in the hypervariable region of mtDNA genome (Supplementary Table 13).

\section{Discussion}

It seems that these hyper resonances of 6765 bases are the conflicting union of the two types of concurrent and independent resonances: CA/TCAG resonances that are DECREASED by mutations on the one hand and G/TCAG resonances which are predominantly DECREASED By mutations, on the other hand. These two types of INDEPENDENT resonances thus act in the same direction under the effect of the mutations.

Final synthetic overview: Let us therefore analyze in greater detail this mechanism of Fibonacci "Hyper Constraints Super Resonances." It is instructive to analyze more fully the distribution and combinatorics of these Fibonacci Hyper Constraints Super Resonances Figure 24: Consider, for example, the first of these 7 resonances:

$\begin{array}{llll}\text { T } & \text { C } & \text { A } & \text { G } \\ 1597 & 2043 & 2138 & 987\end{array}$

There is in fact a combinatorial of 15 possibilities of separation of the bases TCAG: All 4 TCAG bases are combinations of bases by 3 , there are 4 in number; combinations of bases by 2 , there are 6 ; the basic combinations by 1 , there are 4 of them.

How many of these combinations are Fibonacci numbers? Recall the 2 suites of Fibonacci and Lucas: FIBONACCI: 01123581321 3455891442333776109871597258441816765109461771128657 4636875025121393196418317811.

LUCAS: 21347111829477612319932252184313642207 357157789349151272447639603

Then: $\mathrm{TCAG}=6765$

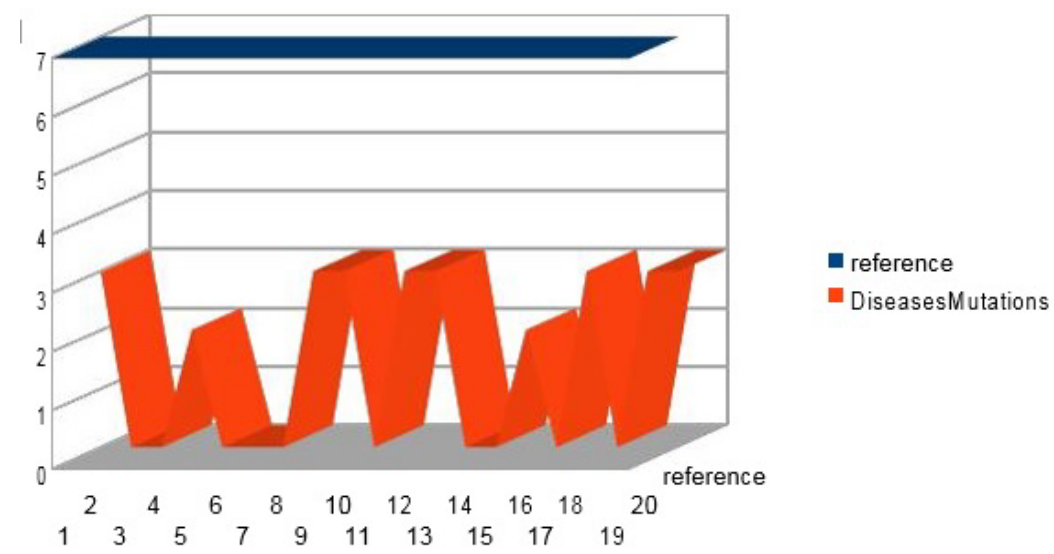

Figure 18: Fibonacci « hyper constraints super resonances » in the case of 20 mutations of Table 2. 


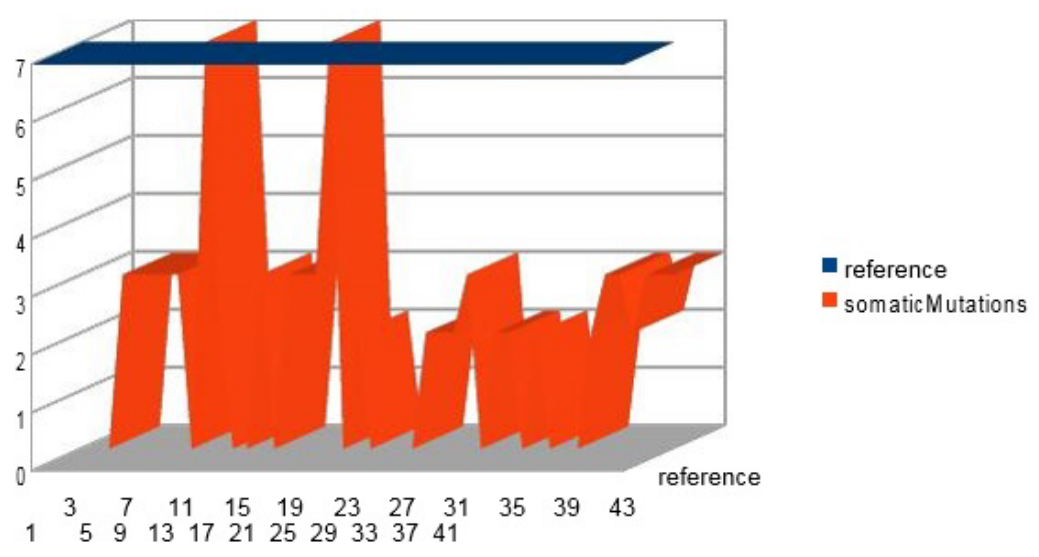

Figure 19: Fibonacci «hyper constraints super resonances» in the case of 44 somatic mutations of Table 4.

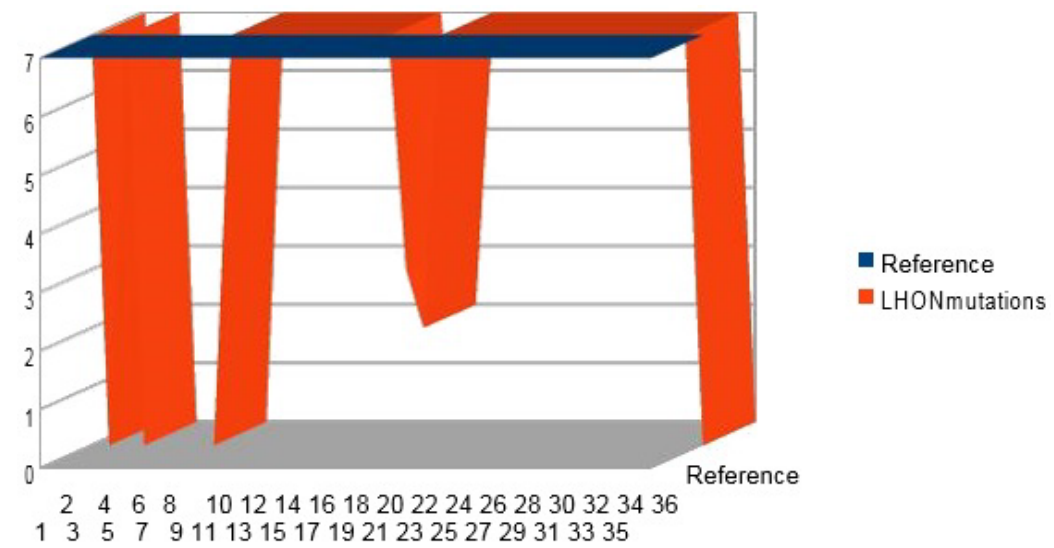

Figure 20: Fibonacci « hyper constraints super resonances » in the case of 36 LHON mutations of Tables 7 and 8. Total adding the 100 Mutations.

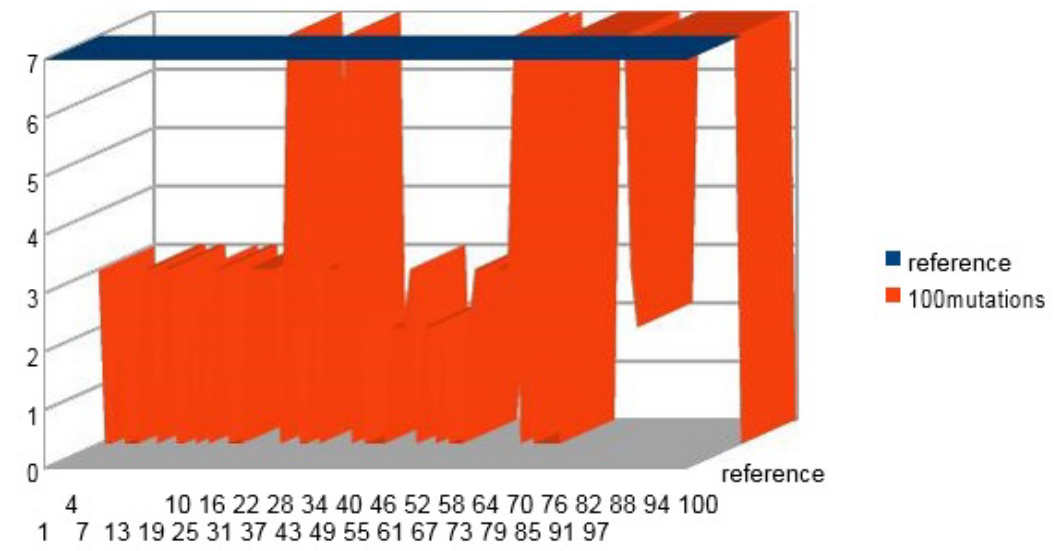

Figure 21: Synthesis Fibonacci « hyper constraints super resonances » in the cumulated cases of 100 various mutations.

$\mathrm{CAG}=\mathrm{CA}+\mathrm{G}=2584+987=3571$. Which is a number of Lucas TAG=?; TC $\mathrm{G}=$ ?

$\mathrm{TCA}=\mathrm{T}+\mathrm{CA}=1597+4181=5778$. Which is a number of Lucas $\mathrm{TC}=$ ?; $\mathrm{TA}=$ ?

\section{$\mathrm{TG}=2584 ; \mathrm{CA}=4181 ; \mathrm{CG}=$ ?; $\mathrm{AG}=$ ?; $\mathrm{T}=1597 \mathrm{C}=$ ?; $\mathrm{A}=$ ? $\mathrm{G}=987$}

Finally, there are 7 combinations (in the 2 sequences of Fibonacci and Lucas above) among the possible 15 are of Fibonacci or Lucas numbers. This constitutes a very high level of constraint that applies to the relative proportions of TCAG bases involved in a "Fibonacci Hyper Constraints Super Resonances".

Another interesting remark is the following: Perez [25-27] have demonstrated the existence of a fine-tuning on the global scale of triplet codon populations of chromosomes and even of the whole genome. Particularly, Chargaff's law [28] where $(\mathrm{T}=\mathrm{A})$ and $(\mathrm{C}=\mathrm{G})$ continues to apply to the single-stranded DNA scale. However, if we analyze the 


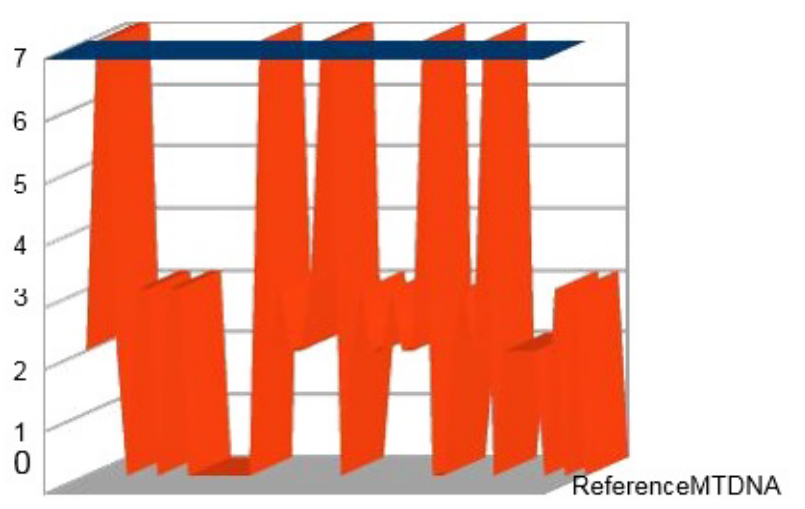

- ReferenceMTDNA

- 50hyperloopsomatics

$3 \quad 711151923273135394347$

15913172125293337414549

Figure 22: Fibonacci « hyper constraints super resonances » for these 100 new cases of somatic mutations.

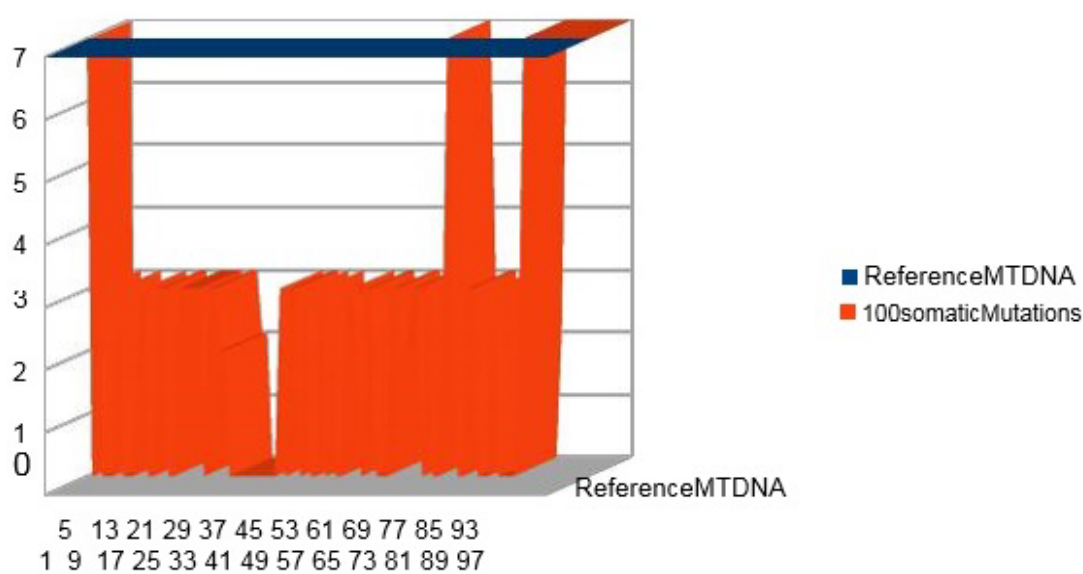

Figure 23: Analysing Fibonacci « hyper constraints super resonances » in 50 somatics mutations from hyperloop region.

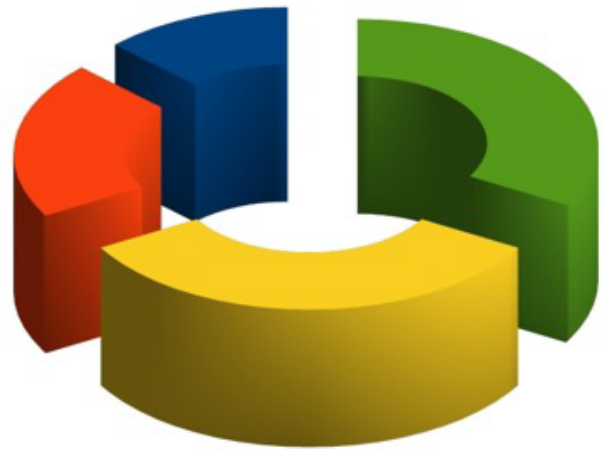

- $987 \mathrm{G}$

$\square 1597 \mathrm{~T}$

$=2584 \mathrm{~T}+\mathrm{G}$

$\because 181 \mathrm{~A}+\mathrm{C}$

Figure 24: Double embedded constraints of the 6765 TCAG « Fibonacci hyper constraints super resonances.

distributions $\mathrm{T} / \mathrm{A}$ and $\mathrm{C} / \mathrm{G}$ in a hyper resonance such as the one just described above, we observe an imbalance: indeed, $\mathrm{C}$ and $\mathrm{A}$ are very close while $\mathrm{T} / \mathrm{G}=\mathrm{Phi}$. Hence, inside this hyper resonance, $\mathrm{T}$ is very different from $\mathrm{A}$ just as $\mathrm{C}$ is very different from G. The Chargaff's law is therefore not respected in the single strand of a hyper resonance. However, let us suppose that the mitochondrial DNA rewinds according to a Moebius ribbon [29], then, facing the 7 hyper resonances $C=A$ and $T / G=P h i$ will face 7 other hyper perfect resonances: $G=T$ and $A /$ $\mathrm{C}=\mathrm{Phi}$. Then this new genome will have $7+7$ hyper resonances perfectly respecting Chargaff's law: $\mathrm{T}=\mathrm{A}$ and $\mathrm{C}=\mathrm{G}$. Details of this Moebius strip mtDNA change:

GATCACAG .../... TCACGATG

CTAGTGTC .../... AGTGCTAC

$==>$

GATCACAG .../... TCACGATG linked with CTAGTGTC .../... AGTGCTAC 
Citation: Perez JC (2017) Sapiens Mitochondrial DNA Genome Circular Long Range Numerical Meta Structures are Highly Correlated with Cancers and Genetic Diseases mtDNA Mutations. J Cancer Sci Ther 9: 512-527. doi: 10.4172/1948-5956.1000469

CTAGTGTC .../... AGTGCTAC GATCACAG .../... TCACGATG Then in images (Figures 25 and 26).

Let us verify at the scale of the entire genome this same imbalance (Table 6).

In both cases: $(\mathrm{T}+\mathrm{A}) /(\mathrm{C}+\mathrm{G})=1.25414966$. It will be noted that this value is close to $5 / 4=1.25$ with an error of 0.00414966 . This Moebius ribbon-like scenario resulting from a sort of "twist of a half turn" of the DNA molecule deserves to be explored.

\section{Conclusion}

In research fields, it is sometimes necessary to "leave time to time"; indeed, the methods and premises of the research that has just been presented here took root as early as the end of the 1980s, so nearly 30 years ago.

Infinite diversity of digital and fractal structures of DNA and genomes: During our Artificial Intelligence research at IBM, based on our model "Fractal Chaos" [30-32], we demonstrated the numerical hyper-sensitivity of an artificial neural network positioned in the vicinity of Phi and subjected to perturbations of Fibonacci number type $[33,34]$.

The fractal architecture [35,36], mathematics [37] and Phi the golden number are omnipresent in nature, in humans, in DNA, and even on the atomic scale [38]. It is a serious mistake to fall into these simplistic theses of an omnipresence of the golden number in the DNA as well as an omnipresence of waves in the DNA.

The reality that we have discovered for more than 25 years of biomathematic exploration of DNA is much subtler: Phi the golden ratio [39-43] and the Fibonacci numbers never appear in the same form according to the scale and level of genetic information studied: In 1991 [21] we discovered sets of Fibonacci numbers structuring

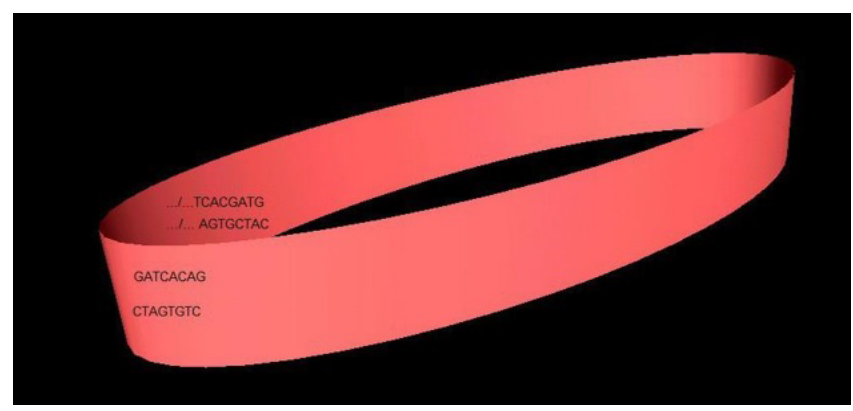

Figure 25: Regular double stranded mtDNA genome.

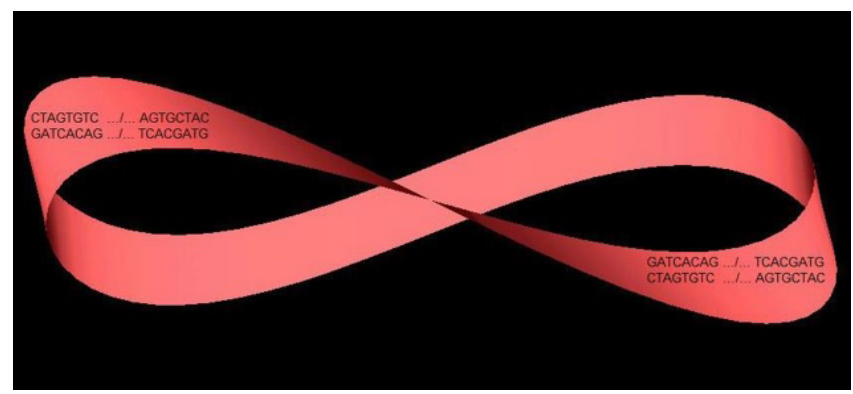

Figure 26: MOEBIUS like double stranded mtDNA genome where single strand 1 is linked with single strand 2 and vice-versa. the proportions of bases TCAG within the genes sequences as well as small genomes dense in genes such as those of bacteria or, specifically, mtDNA but these proportions called "resonances" are absent in junkDNA uncoding chromosomes regions.

In 1997 [25,44] we discovered that a numerical law of projection of the atomic masses of the nucleotides, bioatoms and amino acids, law based on $\mathrm{Pi}$ and Phi, unifies the 3 languages of the genetics that are DNA, RNA, and amino acids.

In $2009[45,46]$ we demonstrated that the fractal texture of the above unified genomic and proteomic images is manifested in the form of periodic discrete waves.

Finally, from 2010 [26,27] we published various articles demonstrating that the golden ratio controls and finely adjusts the proportions of triplets codons to the scale of the entire human genome. This multi-level diversity of Phi is as astonishing as it is radiant.

For example, facing the "pentade" formed by the five discoveries presented in this article on the one hand, in [22,47-49] on the other hand we can only remain amazed.

In "The Human Genome Optimum: A numerical universal law control of all chromosomal deletions involved in human cancers" [48] we showed that there is a sort of HGO (human genome optimum) uniting the entire human genome. This HGO will then allow the

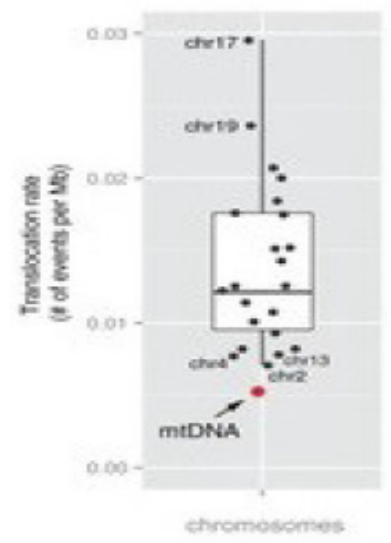

Figure 27: Frequencies of somatic nuclear mtDNA integrations compared to the frequency between autosomes.

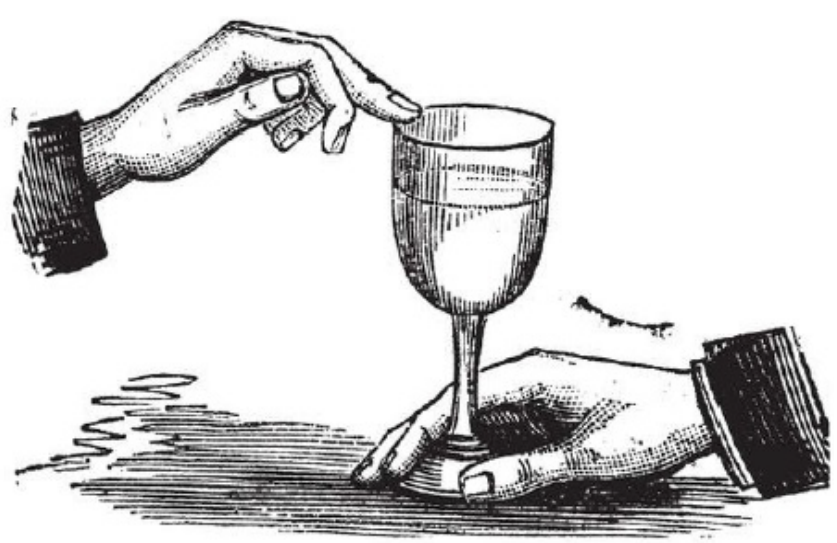

Figure 28: " physical harmonic resonance » analogy scenario (thanks picture from Dr Robert Friedman). 
discovery of a universal law guiding all the LOH deletions implied in the cancers.

In "Humans and Primates Chromosomes 4 Fractal CODES: periodic stationnary waveforms charaterizing and differentiating Neanderthal and Sapiens whole chromosomes DNA sequences" [22] we showed a sort of hierarchy classifying the 24 human chromosomes. One of them, the chromosome 4 would be a kind of leader, "lighthouse" and this lighthouse vibrates to the proportions of Phi, the numbers of Lucas and Fibonacci.

Finally, in [47] we discovered stranger still: Phi and the numbers of Fibonacci and Lucas no longer appear explicitly. They hide behind a subtle interference, hiding behind a spectrum of numerical periods in the appearance of any numbers.

Our intuition is that there is a link, "dialogues" between these three heterogeneous but subtle disparate mechanisms that are mathematics, fractals, and the numbers of Fibonacci, Lucas, and Golden ratio.

Thus, in revisiting here the "supracode of DNA" discovered since the beginning of the 90s, as Professor Luc Montagnier baptized it [50], here we "rewind" this vast trip around digital structures of DNA and genomes like the mtDNA genome, would the loop be "looped".

However, many questions will remain to be explored as a result of this research, for example: What happens if the mtDNA genome accidentally loops back into Moebius ribbon [29]?

As Tomasetti demonstrates in [51], "a substantial fraction of mutations in human cancer are attributable to random errors occurring during DNA replication." So- if they affect the mtDNA genome- how could these erratic somatic mutations perhaps trigger the origin of cancers?

How did the subtle mechanisms of human evolution lead to Sapiens $[47,49,52,53]$ ? What was the role of the mtDNA genome?

However, these numerical structures that we discover here could generate phenomena of electronic [22], even oscillatory [22] and undulatory [54,55] conductivity? How do these fractal structures $[32,40,56]$ of DNA contribute to the dynamics of epigenetic folds?

Finally, how this "HomOGM" of Neanderthal proposed as of 1999, as just presented in the Perspectives $\S$, could today be realized thanks to the technology CRISPR [57] to open this era of fusion between genetic man and AI (Artificial Intelligence) so much desired by transhumanists $[58,59]$ ?

Finally, the major fact of this research is the following: how and why- systematically- mtDNA mutations associated with pathogenic cases- NEVER lead (100\% of the cases studied) to a reduction in long resonances $(\mathrm{C}+\mathrm{A}) /(\mathrm{T}+\mathrm{G})$ while hyper constraints super resonances decrease in $100 \%$ of the 250 cases of pathogenic mutations analyzed? What happens then in these pathogenic cells whose mitochondrial genome would seem more "optimal"? This genomic optimality leads to an energetic over-functioning of the mitochondria of this pathogenic cell [60], which could explain the extreme pathogenicity and the disturbances observed in these pathogenic cells, especially in the cases of this cancerous cells, Beyond the theoretical aspect of this article, it is indeed the field of potential applications that will have to be explored tomorrow.

Another interesting topic that should be studied is the possible INTERACTION between the nuclear genome and the human mitochondrial genome [61]. Indeed, it has been demonstrated [62] that in certain cancer cells, fragments of mtDNA migrate to certain chromosomes of the nuclear genome. Effectively, Mitochondrial genomes are separated from the nuclear genome for most of the cell cycle by the nuclear double membrane, intervening cytoplasm, and the mitochondrial double membrane. Despite these physical barriers, Dr Young et al. [62] showed that somatically acquired mitochondrial-nuclear genome fusion sequences are present in cancer cells. Remarkably, mitochondrial-nuclear genome fusions occur at a similar rate per base pair of DNA as interchromosomal nuclear rearrangements, indicating the presence of a high frequency of contact between mitochondrial and nuclear DNA in some somatic cells (Figure 27) [62].

Particularly, in the part B of Figure $26 \mathrm{Ju}$ et al. [62] represented frequencies of somatic nuclear mtDNA integrations compared to the frequency between autosomes (chromosomal translocation). We note that chromosomes classification ( $\operatorname{chr} 4,13,2, \ldots / \ldots .17$ 19) are in accord with the chromosomal hierarchy classification that we demonstrate in published paper [44] and in future paper [22].

It is then interesting to ask whether there is no relationship between the proportions of Fibonacci observed on the one hand, here in the mtDNA genome, and on the other hand, in certain chromosomes of the nuclear genome?

Indeed, we will demonstrate that at the scale of the entire human chromosome 4 and chromosome 13 , the ratio $(\mathrm{C}+\mathrm{G}) /(\mathrm{T}+\mathrm{A})=1 / \mathrm{Phi}[48]$.

On the other hand, in the 152 resonances $28651(\mathrm{C}+\mathrm{A}) /(\mathrm{T}+\mathrm{G})$ of the Table 1 and in the 7 "Fibonacci Hyper Constraints Super Resonances" $6765(\mathrm{C}+\mathrm{A}) /(\mathrm{T}+\mathrm{G})=$ Phi the Golden ratio. Now, we know that Phi- $(1 / \mathrm{Phi})=1$.

Hence, there may be hypothetical "information couplings", the nature of which would be undulatory $[22,54]$ between, on the one hand, this famous chromosome 4 and, on the other hand, these specific resonances of the mtDNA genome. And this, magicked the boundaries of membranes separating these two respective genomes in the cell.

Another track of investigations is the scenarii of physical harmonic resonance as sugested Dr Robert Friedman. Do you think that circular mtDNA with the right number of Fibonacci resonance points could act like a singing wine glass? When you rub a finger around the rim of the glass, harmonic energy, tones or information are produced. This could be a mechanism that mitochondria and cells use to communicate with each other. This scenarii could play a role in mtDNA genome epigenetics then in genes expression tuning (Figure 28).

However, the major conclusion seems to be the following: All the human genetic heritage is concentrated in 2 genomes: the nuclear genome and its 23 pairs of chromosomes on the one hand, and the small mitochondrial genome mtDNA, on the other hand.

The majority of mutations associated with genetic diseases as well as all cancers most often lead to deletions affecting each of these 2 genomes. Then, in the article "The Human Genome Optimum: A numerical universal law controling all $\mathrm{LOH}$ chromosomal deletions involved in human cancers" [48], article, we demonstrate that all these mutations unbalance, for both genomes, a kind of optimum of each of these genomes. This is probably the major result that we will have to continue to reflect on and experiment with. In particular, it is necessary to explore, according to our method, the possible relations existing between the mutations of the nuclear genome and the mitochondrial genome involved in the tumour cells $[63,64]$. 
Citation: Perez JC (2017) Sapiens Mitochondrial DNA Genome Circular Long Range Numerical Meta Structures are Highly Correlated with Cancers and Genetic Diseases mtDNA Mutations. J Cancer Sci Ther 9: 512-527. doi: 10.4172/1948-5956.1000469

Finally, our approach may be related to these hundreds of unpredictable mutations resulting from manipulation of genomes by CRISPR revolutionary technology [65]. Effectively in their 2017 article, authors note that they found that the technique had successfully corrected a gene that causes blindness in the mice, but the two mice that had undergone CRISPR gene-editing had sustained more than 1,500 unintended single-nucleotide mutations, and more than 100 larger deletions and insertions [66].

\section{Funding}

This publication was supported by "Luc Montagnier Foundation (Geneve switzerland) Fondation Luc Montagnier, Quai Gustave-Ador 62, 1207 Genève, Suisse, 41225356999

\section{Acknowledgements}

We especially thank Dr. Robert Friedmann M.D. practiced nutritional and preventive medicine in Santa Fe, New Mexico, which suggested new research interest on mtDNA genome. We also thank the mathematician Pr. Diego Lucio Rapoport (Buenos aires), the french biologist Pr. François Gros (Pasteur institute, co-discoverer of RNA messenger with James Watson and Walter Gilbert) and Pr. Luc Montagnier, medicine Nobel prize winner for their interest in my research of biomathematical laws of genomes.

\section{References}

1. Perez JC (1991) Chaos DNA and neuro-computers: A golden link. Speculat Sci Technol 14: 336-346.

2. Marcer PJ (1992) Order and chaos in DNA- The Denis Guichard Prizewinner: Jean-Claude Perez. Kybernetes 21: 60-61.

3. Kogelnik AM, Lott MT, Brown MD, Navathe SB, Wallace DC (1996) MITOMAP A human mitochondrial genome database. Nucleic acids res 24: 177-179.

4. Shoffner JM, Lott MT, Lezza AM, Seibel P, Ballinger SW, et al. (1990) Myoclonic epilepsy and ragged-red fiber disease (MERRF) is associated with a mitochondrial DNA tRNALys mutation. Cell 61: 931-937.

5. Wallace DC, Brown MD, Lott MT (1999) Mitochondrial DNA variation in human evolution and disease. 238: 211-230.

6. Wallace DC (1987) Maternal genes: Mitochondrial diseases. In Medical and experimental mammalian genetics: A perspective (McKusick VA, Roderick TH, Mori J, Paul MW) (eds) 23: 137-190.

7. Wallace DC, Chalkia D (2013) Mitochondrial DNA genetics and the heteroplasmy conundrum in evolution and disease. Cold Spring Harbor perspectives in biology 5: a021220.

8. Shabalina IG (2017) Improved health-span and lifespan in mtDNA mutator mice treated with the mitochondrially targeted antioxidant SkQ1 Aging (Albany NY). 9: 315-339.

9. Larsson NG (2010) Somatic mitochondrial DNA mutations in mammalian aging. Annu Rev Biochem 79: 683-706.

10. Schon EA, DiMauro S, Hirano M (2012) Human mitochondrial DNA: Roles of inherited and somatic mutations. Nature Rev Gene 13: 878-890.

11. Green RE, Malaspinas AS, Krause J, Briggs AW, Johnson PL, et al. (2008) A complete Neandertal mitochondrial genome sequence determined by highthroughput sequencing. Cell. 134: 416-426.

12. Sawyer S, Renaud G, Viola B, Hublin JJ, Gansauge MT, et al. (2015) Nuclear and mitochondrial DNA sequences from two Denisovan individuals. P Natl Acad Sci 112: 15696-15700.

13. Krings M, Stone A, Schmitz RW, Krainitzki H, Stoneking M, et al. (1997) Neandertal DNA sequences and the origin of modern humans. Cell 90: 19-30.

14. Krings M, Geisert H, Schmitz RW, Krainitzki H, Pääbo S (1999) DNA sequence of the mitochondrial hypervariable region II from the Neandertal type specimen. Proc Natl Acad Sci USA 96: 5581-5585.

15. Duarte C, Maurício J, Pettitt PB, Souto P, Trinkaus E, et al. (1999) The early upper Paleolithic human skeleton from the Abrigo do Lagar Velho (Portugal) and modern human emergence in Iberia. Proc Natl Acad Sci 96: 7604-7609.

16. GenBank. Pan troglodytes mitochondrial DNA, complete genome (isolate Jenny). FASTA X93335.1
17. Defleur A, White T, Valensi P, Slimak L, Crégut-Bonnoure E (1999) Neanderthal Cannibalism at Moula-Guercy, Ardèche, France. Science 286: 128-131.

18. Fogleman S, Santana C, Bishop C, Miller A, Capco DG (2016) CRISPR/Cas9 and mitochondrial gene replacement therapy: Promising techniques and ethical considerations. Am J Stem Cells 5: 39-52.

19. Wallace DC (1999) Mitochondrial diseases in man and mouse. Science 283 1482-1488.

20. Wallace DC, Murdock DG (1999) Mitochondria and dystonia: The movement disorder connection? Proc Natl Acad Sci U S A 96: 1817-1819.

21. Perez JC (1997) L’ADN décrypté. Résurgence, Liege.

22. Perez JC (2017) Humans and primates chromosomes 4 Fractal CODES Periodic stationnary waveforms charaterizing and differenciating Neanderthal and Sapiens whole chromosomes DNA sequences.

23. Ratner M (1999) Photochemistry: Electronic motion in DNA. Nature 397: 480-481.

24. Koehler CM, Leuenberger D, Merchant S, Renold A, Junne T, et al. (1999) Human deafness dystonia syndrome is a mitochondrial disease. Proc Natl Acad Sci U S A 96: 2141-2146.

25. Perez JC (2009) Codex Biogenesis. Resurgence, Liege Belgium.

26. Perez JC (2010) Codon populations in single-stranded whole human genome DNA Are Fractal and fine-tuned by the golden ratio 1.618. Interdisciplinary Sciences: Computational Life Sciences 2: 1-13.

27. Perez JC (2013) The "3 Genomic Numbers" Discovery: How our genome single-stranded DNA sequence is "self- designed" as a numerical whole. App Math 4: 37-53.

28. http://hvc.rutgers.edu/sites/default/files/coursefiles/courses_f12/127/ protected/2012-127-Ch-12-2.pdf.

29. Rapoport DL (2016) The Klein Bottle logic of genomics and its dynamics, quantum information, complexity and palindromic repeats in evolution. Quantum Biosystems 7: 107-174.

30. Perez JC (1988) De nouvelles voies vers l'intelligence artificielle: Pluridisciplinarite: auto-organisation: réseaux neuronaux, Masson Paris.

31. Perez JC (1990) La révolution des ordinateurs neuronaux, Hermès Paris.

32. Perez JC, Bertille JM (1988) "FRACTAL CHAOS" a new neural network holographic model. Neural Networks 1: 121.

33. Perez JC (1990) Digital holograms computers, concepts and applications Neural networks: biological computers or electronic brains, Les entretiens de Lyon. Springer 2-87.

34. Perez JC (1990) Integers neural network systems (INNS) using resonance properties of a Fibonacci's chaoticgolden neuron'. In Neural Networks, 1990, 1990 IJCNN International Joint Conference. pp. 859-865

35. Pellionisz AJ, Graham R, Pellionisz PA, Perez JC (2012) Recursive Genome function of the cerebellum: Geometric unification of neuroscience and genomics. Handbook of the cerebellum and cerebellar disorders. (1st edn), Springer, USA.

36. Dokukin ME, Guz NV, Woodworth CD, Sokolov I (2015) Emergence of fractal geometry on the surface of human cervical epithelial cells during progression towards cancer. New J Phys 17: 033019.

37. Petoukhov S (2011) Mathematics of bioinformatics: Theory, methods and applications. (1st edn), John Wiley \& Sons, USA.

38. Coldea R, Tennant DA, Wheeler EM, Wawrzynska E, Prabhakaran D (2010) Quantum criticality in an ising chain: Experimental evidence for emergent E8 symmetry. Science 327 : 177-180

39. Friedman R, Cross M (2013) The Golden Ratio and Fibonacci Sequence: Golden Keys to Your Genius, health, wealth and excellence. (1st edn), Hoshin Media, USA.

40. Persaud D, O'Leary JP (2015) Fibonacci series, golden proportions, and the human biology.

41. Li H, Zhu D, Zhang C, Han H, Crandall KA (2014) Characteristics and prediction of RNA structure. Biomed Res Int 2: 1-6

42. Vaezi A, Barkeshli M (2014) Fibonacci anyons from abelian bilayer quantum hall states. Phys Rev Lett 113: 236804 
Citation: Perez JC (2017) Sapiens Mitochondrial DNA Genome Circular Long Range Numerical Meta Structures are Highly Correlated with Cancers and Genetic Diseases mtDNA Mutations. J Cancer Sci Ther 9: 512-527. doi: 10.4172/1948-5956.1000469

43. Olsen SA (2017) Riding the numbers: Ratios and resonant states of consciousness, sociology and anthropology 5: 72-75

44. Perez JC (2015) Deciphering hidden DNA meta-codes-The great unification and master code of biology. J Glycomics Lipidomics 5: 1.

45. Perez JC (2011) Caminos interdisciplinaios. Seminario CLAVE INTER, Espacio Interdisciplinario, Universidad de la Republica Montevideo, Uruguay.

46. Perez JC (2011) Decoding non-coding DNA codes: Human genome metachromosomes architecture. BIT Life Sciences' 3rd Annual World Vaccine Congress, Beijing, China.

47. Perez JC (2017) 41-DUF1220 Homo sapiens fractal periods architectures breakthrough.

48. Perez JC The Human Genome Optimum: a numerical universal law controling all LOH chromosomal deletions involved in human cancers ".

49. Perez JC (2017) Global and long-range fractal differences between sapiens and neanderthal genomes.

50. Rachel Fleaux (1995) La Musique des genes, in SCIENCES \& AVENIR French magazine.

51. Tomasetti C, Li L, Vogelstein B (2017) Stem cell divisions, somatic mutations, cancer etiology, and cancer prevention. Science 355: 1330-1334.

52. Weiss V (2017) Das IQ-Gen- Verleugnet seit 2015. Eine bahnbrechende Entdeckung und ihre Feinde. Graz: Ares.

53. Marshall P (2011) Evolution 2.0. Benbella Books, USA.

54. Montagnier L, Aïssa J, Ferris S, Montagnier JL, Lavallée C (2009) Electromagnetic signals Are produced by aqueous nanostructures derived from bacterial DNA sequences. Interdiscip Sci Comput Life Sci 1: 81-90.

55. Boeyens_Levendis-Number_Theory_and_the_Periodicity_of_Matter.
56. Lieberman-Aiden E, Van Berkum NL, Williams L, Imakaev M, Ragoczy T (2009) Comprehensive mapping of long-range interactions reveals folding principles of the human genome. Science 326: 289-293.

57. Suzuki K, Tsunekawa Y, Hernandez-Benitez R, Wu J, Zhu J, et al. (2016) In vivo genome editing via CRISPR/Cas 9 mediated homology-independent targeted integration. Nature 540: 144-149.

58. Yampolskiy RV (2016) On the origin of synthetic life: Attribution of output to a particular algorithm. Physica Scripta 92: 013002.

59. Elon Musk's (2017) New startup wants to merge human brains with computers FORTUNE.

60. Smith DR (2016) The past, present and future of mitochondrial genomics: Have we sequenced enough mtDNAs? Brief Funct Genomics 15: 47-54.

61. Anderson S, Bankier AT, Barrell BG, De Bruijn MH, Coulson AR (1981) Sequence and organization of the human mitochondrial genome. NATURE 290: 457-465.

62. Ju YS, Tubio JM, Mifsud W, Fu B, Davies HR (2015) Frequent somatic transfer of mitochondrial DNA into the nuclear genome of human cancer cells. Genome Res 25: 814-824.

63. Davis CF, Ricketts CJ, Wang M, Yang L, Cherniack AD (2014) The somatic genomic landscape of chromophobe renal cell carcinoma. Cancer Cell 26: 319-330.

64. McMahon S, La Framboise T (2014) Mutational patterns in the breast cancer mitochondrial genome, with clinical correlates. Carcinogenesis 35: 1046-1054.

65. Schaefer KA, Wu WH, Colgan DF, Tsang SH, Bassuk AG (2017) Unexpected mutations after CRISPR-Cas9 editing in vivo. Nat Methods 14: 547-548.

66. Perez JC (2017) Fractal self-similarity, scale invariance and stationary waves codes architecture human chromosomes DNA sequences. 